\title{
The clinical use of stress echocardiography in ischemic heart disease
}

\author{
Rosa Sicari ${ }^{*}$ (D) and Lauro Cortigiani ${ }^{2}$
}

\begin{abstract}
Stress echocardiography is an established technique for the assessment of extent and severity of coronary artery disease. The combination of echocardiography with a physical, pharmacological or electrical stress allows to detect myocardial ischemia with an excellent accuracy. A transient worsening of regional function during stress is the hallmark of inducible ischemia. Stress echocardiography provides similar diagnostic and prognostic accuracy as radionuclide stress perfusion imaging or magnetic resonance, but at a substantially lower cost, without environmental impact, and with no biohazards for the patient and the physician.

The evidence on its clinical impact has been collected over 35 years, based on solid experimental, pathophysiological, technological and clinical foundations. There is the need to implement the combination of wall motion and coronary flow reserve, assessed in the left anterior descending artery, into a single test. The improvement of technology and in imaging quality will make this approach more and more feasible. The future issues in stress echo will be the possibility of obtaining quantitative information translating the current qualitative assessment of regional wall motion into a number. The next challenge for stress echocardiography is to overcome its main weaknesses: dependance on operator expertise, the lack of outcome data (a widesperad problem in clinical imaging) to document the improvement of patient outcomes. This paper summarizes the main indications for the clinical applications of stress echocardiography to ischemic heart disease.
\end{abstract}

\section{Background}

\section{Pathophysiologic mechanisms}

Stress echocardiography is the combination of 2D echocardiography with a physical, pharmacological, or electrical stress [1]. The diagnostic endpoint for the detection of myocardial ischaemia is the induction of a transient change in regional function during stress. A transient regional imbalance between oxygen demand and supply usually results in myocardial ischaemia, the signs and symptoms of which can be used as a diagnostic tool [1]. Myocardial ischaemia results in a typical 'cascade' of events in which the various markers are hierarchically ranked in a well-defined time sequence [2]. Flow heterogeneity, especially between the subendocardial and subepicardial perfusion, is the forerunner of ischaemia, followed by metabolic changes, alteration in regional mechanical function, and only at a later stage by electrocardiographic changes, and pain. The

\footnotetext{
* Correspondence: rosas@ifc.cnr.it

${ }^{1}$ CNR, Institute of Clinical Physiology, Via G. Moruzzi, 1, 56124 Pisa, Italy Full list of author information is available at the end of the article
}

pathophysiological concept of the ischaemic cascade is translated clinically into a gradient of sensitivity of different available clinical markers of ischaemia, with chest pain being the least and regional malperfusion the most sensitive. The reduction of coronary flow reserve (CFR) is the common pathophysiological mechanism. Regardless of the stress used and the morphological substrate, ischaemia tends to propagate centrifugally with respect to the ventricular cavity: $[3,4]$ it involves primarily the subendocardial layer, whereas the subepicardial layer is affected only at a later stage if the ischaemia persists [4]. In fact, extravascular pressure is higher in the subendocardial than in the subepicardial layer; this provokes a higher metabolic demand (wall tension being among the main determinants of myocardial oxygen consumption) and an increased resistance to flow. In the absence of coronary artery disease (CAD), CFR can be reduced in microvascular disease (e.g. in syndrome $\mathrm{X}$ ) or left ventricular (LV) hypertrophy (e.g. arterial hypertension). In this condition, angina with ST-segment depression can occur with regional perfusion changes, typically in the absence of any regional wall motion abnormalities during stress. Wall 
motion abnormalities are more specific than CFR and/or perfusion changes for the diagnosis of CAD [5-10].

\section{Diagnostic criteria}

All stress echocardiographic diagnoses can be summarized into four equations centered on regional wall function and describing the fundamental response patterns: normal, ischemic, necrotic, and viable.

\section{Normal response}

A segment is normokinetic at rest and normal or hyperkinetic during stress.

\section{Ischemic response}

The function of a segment worsens during stress from normokinesia to hypokinesia (decrease of endocardial movement and systolic thickening), akinesia (absence of endocardial movement and systolic thickening), or dyskinesia (paradoxical outward movement and possible systolic thinning). However, a resting akinesia becoming dyskinesia during stress reflects purely passive phenomenon of increased intraventricular pressure developed by normally contracting walls and should not be considered a true active ischemia [1].

\section{Necrotic response}

A segment with resting dysfunction remains fixed during stress.

\section{Viability response}

A segment with resting dysfunction may show either a sustained improvement during stress indicating a nonjeopardized myocardium (stunned) or improve during early stress with subsequent deterioration at peak (biphasic response). The biphasic response is suggestive of viability and ischemia, with jeopardized myocardium fed by a critically coronary stenosis [1] Table 1 .

\section{Ischaemic stressors}

Exercise, dobutamine, and dipyridamole are the most frequently used stressors for echocardiographic test [11]. There are distinct advantages and disadvantages to exercise versus pharmacological stress. In Table 2 the stress echo protocols are reported.

Table 1 Stress echocardiography in 4 equations

\begin{tabular}{lllll}
\hline Rest & + & Stress & $=$ & Diagnosis \\
\hline Normokinesis & + & Normo-Hyperkinesis & $=$ & Normal \\
Normokinesis & + & Hypo, A, Dyskinesis & $=$ & Ischaemia \\
Akinesis & + & Hypo, Normokinesis & $=$ & Viable \\
A-, Dyskinesis & + & A-, Dyskinesis & $=$ & Necrosis \\
\hline
\end{tabular}

Table 2 Stress echo protocols

\begin{tabular}{|c|c|c|}
\hline Test & Equipment & Protocols \\
\hline Exercise & $\begin{array}{l}\text { Semi-supine bycicle } \\
\text { ergometer }\end{array}$ & $\begin{array}{l}25 \mathrm{~W} \times 2^{\prime} \text { with incremental } \\
\text { loading }\end{array}$ \\
\hline Dobutamine & Infusion Pump & $\begin{array}{l}5 \mathrm{mcg} / \mathrm{Kg} / \mathrm{min} 10-20-30-40+ \\
\text { atropine }(0.25 \times 4) \text { up to } 1 \mathrm{mg}\end{array}$ \\
\hline Dipyridamole & Syringe & $\begin{array}{l}0.84 \mathrm{mg} / \mathrm{Kg} \text { in } 6^{\prime} \text { or } 0.84 \mathrm{mg} / \mathrm{Kg} \\
\text { in } 10^{\prime}+\text { atropine }(0.25 \times 4) \mathrm{up} \\
\text { to } 1 \mathrm{mg}\end{array}$ \\
\hline Adenosine & Syringe & $140 \mathrm{mcg} / \mathrm{Kg} / \mathrm{min}$ in $6^{\prime}$ \\
\hline Pacing & External Pacing & $\begin{array}{l}\text { From } 100 \mathrm{bpm} \text { with increments } \\
\text { of } 10 \text { beats/min up to target } \\
\text { heart rate }\end{array}$ \\
\hline
\end{tabular}

\section{Exercise}

Exercise echocardiography can be performed using either a treadmill or bicycle protocol. When a treadmill test is performed, post-exercise imaging is evaluated. Regional wall motion abnormalities would persist long enough into recovery to be detected but when recovery is rapid false-negative results occur [11]. Some Authors [12], perform peak-exercise imaging also during treadmill by keeping the patient standing still. Although challenging such an approach avoid false negative results in case of a rapid recovery to resting conditions. Information on exercise capacity, heart rate response, and rhythm and blood pressure changes are analysed and, together with wall motion analysis, become part of the final interpretation [11]. Bicycle exercise echocardiography is performed during either an upright or a recumbent posture. Unlike treadmill test, bicycle exercise allows to obtain images during the various levels of exercise. The supine position is the most suited for exercise echocardiography due to its ease of image acquisition in all views through the steps of the graded exercise [13]. In the upright posture, imaging is generally limited to apical views.

\section{Dobutamine}

The standard dobutamine stress protocol consists of continuous intravenous infusion of dobutamine in $3 \mathrm{~min}$ increments, starting with $5 \mu \mathrm{g} / \mathrm{kg} / \mathrm{min}$ and increasing to $10,20,30$, and $40 \mu \mathrm{g} / \mathrm{kg} / \mathrm{min}$. If no endpoint is reached, atropine (up to $1 \mathrm{mg}$ ) is added to the $40 \mu \mathrm{g} / \mathrm{kg} / \mathrm{min}$ dobutamine infusion $[11,14,15]$.

\section{Dipyridamole}

The standard dipyridamole protocol consists of an intravenous infusion of $0.84 \mathrm{mg} / \mathrm{kg}$ over $10 \mathrm{~min}$, in two separate infusions: $0.56 \mathrm{mg} / \mathrm{kg}$ over $4 \mathrm{~min}$, followed by $4 \mathrm{~min}$ of no dose and, if still negative, and additional $0.28 \mathrm{mg} / \mathrm{kg}$ over $2 \mathrm{~min}[11,16,17]$. If no endpoint is reached, atropine (up to $1 \mathrm{mg}$ ) is added [18]. The same overall dose of $0.84 \mathrm{mg} / \mathrm{kg}$ can be given over $6 \mathrm{~min}[11,19]$. Aminophylline should be available for immediate use in case an 
adverse dipyridamole-related event occurs and routinely infused at the end of the test independent of the result $[1,11]$.

\section{Adenosine}

Adenosine is usually infused at a maximum dose of $140 \mu \mathrm{g} / \mathrm{kg} / \mathrm{min}$ over $6 \mathrm{~min}[3,20]$. When side-effects are intolerable, down-titration of the dose is also possible.

\section{Pacing}

The presence of a permanent pacemaker can be exploited to conduct a pacing stress test in a totally non-invasive manner by externally programming the pacemaker to increasing frequencies. Pacing is started at $100 \mathrm{bpm}$ and increased every 2 min by $10 \mathrm{bpm}$ until the target heart rate or other standard endpoints are achieved [3,21]. A limiting factor is, however, that several pacemakers cannot be programmed to the target heart rate.

\section{Indications to stress echo}

Indications for stress echocardiography can be grouped in very broad categories which can encompass the majority of patients (see Table 3) [11]:

(i) CAD diagnosis;

(ii) prognosis and risk stratification in patients with established diagnosis (e.g. after myocardial infarction);

(iii)preoperative risk assessment;

(iv)evaluation for cardiac aetiology of exertional dyspnoea;

(v) evaluation after revascularization;

(vi)ischaemia localization;

As a rule, the less informative the exercise ECG test is, the stricter the indication for stress echocardiography will be. Out of five patients, one is unable to exercise, one exercises submaximally, and one exercises maximally but the ECG is uninterpretable.

Table 3 Indications to stress echocardiography

Diagnosis of CAD in patients in whom exercise ECG is contraindicated, not feasible, uninterpretable, non-diagnostic or gives ambiguous results

Risk stratification in patients with established diagnosis

Pre-operative risk assessment (high-risk non emergent, poor exercise tolerance)

Evaluation after revascularization (not in the early post-procedure period, with change in symptoms)

Search for viability in patients with ischemic cardiomyopathy eligible for revascularization

Coronary artery disease of unclear significance at angiography or computed tomography
The three main specific indications for pharmacologic stress echocardiography can be summarized as follows:

(i) patients in whom the exercise stress test is contraindicated (e.g. patients with severe arterial hypertension);

(ii) patients in whom the exercise stress test is not feasible (e.g. those with intermittent claudication);

(iii)patients in whom the exercise stress test was nondiagnostic or yielded ambiguous results: inability to achieve the target heart rate response, presence of chest pain in the absence of significant electrocardiographic changes, and a concomitance of conditions lowering the reliability of the ECG marker of ischemia (female gender, arterial hypertension, repolarization abnormalities on ECG under resting conditions or after hyperventilation, and the need to continue drugs such as digitalis or anti-arrhythmic that potentially induce ST-segment and $\mathrm{T}$ wave changes). Tables 4 and 5 report the main reasons for test interruption.

2013 ESC guidelines on stable CAD have posed a new emphasis on the use of non-invasive imaging due to its significantly higher diagnostic accuracy [22]. However, the real impact of non-invasive imaging as a gate-keeper to coronary angiography need to to be tested on outcomes studies. The reported indications may change over time due to the evidence accumulating on survival impact. Exercise ECG remains a first-line in patients with interpretable ECG due to its simplicity, safety, availability, low cost, and high negative predictive value. Appropriateness criteria that may shed light on the use of stress echocardiography are derived from a balance between hard evidence, expert opinion, clinical experience and common sense.

\section{Diagnostic accuracy}

In a meta-analysis of 55 studies with 3,714 patients, exercise, dobutamine, dipyridamole, and adenosine echocardiography showed a sensitivity, respectively, of 83,81 , 72 , and $79 \%$, and a specificity of $84,84,95$, and $91 \%$ [23]. In another meta-analysis of 5 studies adopting state of the art protocols for dipyridamole (fast or atropinepotentiated) and dobutamine (atropine-potentiated) test,

Table 4 Stress echocardiographic diagnostic criteria

Maximal dose or workload

Target heart rate

Echocardiographic Positivity (new or worsening of wall motion abnormality)

Chest Pain

ECG modification (ST Segment Shift $>2 \mathrm{~mm}$ ) 
Table 5 Submaximal non diagnostic criteria for test interruption

Intolerable symptoms

Hypertension: Systolic Blood Pressure $>220$ mmHg; Diastolic Bllood Pressure $>120 \mathrm{mmHg}$

Hypotension (Absolute or Relative): Blood Pressure Fall > $30 \mathrm{mmHg}$

Supraventricular Arrhythmias: Tachycardia; Atrial Fibrillation

Ventricular Arrhythmias: Ventricular Tachycardia; Polymorphous PVCs

the two stresses had identical sensitivity (84\%) and comparable specificity (92\% vs $87 \%$ ) [24]. When compared to standard exercise electrocardiography, stress echocardiography has a particularly impressive advantage in terms of specificity [25]. Compared to nuclear perfusion imaging, stress echocardiography at least has similar accuracy, with a moderate sensitivity gap that is more than balanced by a markedly higher specificity [23]. Familiarity with all forms of stress is an index of the quality of the echo lab. In this way, indications in the individual patient can be optimised, thereby avoiding the relative and absolute contraindications of each test. For instance, a patient with severe hypertension and/or a history of significant atrial or ventricular arrhythmias can more reasonably undergo to the dipyridamole stress test which, unlike dobutamine, has no arrhythmogenic or hypertensive effect. In contrast, a patient with severe conduction disturbances or advanced asthmatic disease should undergo the dobutamine stress test, since adenosine has a negative chronotropic and dromotropic effect, as well as a documented bronchoconstrictor activity. Patients either taking xanthine medication or under the effect of caffeine contained in drinks (tea, coffee, cola) should undergo the dobutamine test. Both dipyridamole and dobutamine have overall good tolerance and feasibility. The choice of one test over the other depends on patient characteristics, local drug cost and the physician's preference. It is important for all stress echocardiography laboratories to become familiar with all stresses to achieve a flexible and versatile diagnostic approach that enables the best stress to be tailored to individual patient needs. Antianginal medical therapy (in particular, beta-blocking agents) significantly affects the diagnostic accuracy of all forms of stress; therefore, it is recommended, whenever possible, to withhold medical therapy at the time of testing to avoid a false-negative result $[11,26]$.

\section{Prognostic value}

The presence (or absence) of inducible wall motion abnormalities separates patients with different prognoses. Information has been obtained from data banks of thousands of patients - also with multicentre design - for exercise [27-43], dobutamine [44-52], and dipyridamole [25, 47, 53-57]. A normal stress echocardiogram yields an annual risk of $0.4-0.9 \%$ based on a total of $>11000$ patients [43], the same as for a normal stress myocardial perfusion scan (Fig. 1). Thus in patients with suspected CAD, a normal stress echocardiogram implies excellent prognosis and coronary angiography can safely be avoided. The positive and the negative response can be further stratified with interactions with clinical parameters (diabetes, renal dysfunction, and therapy at the time of test), resting echo (global LV function), and additive stress echo parameters (LV cavity dilatation, CFR, and previous revascularization). While the ischemic or necrotic pattern are associated with markedly increased risk of death or myocardial infarction, a normal test is predictive of a generally favorable outcome particularly in nondiabetic patients [58]. The ischemic response can be further stratified with additive stress echo parameters, such as the extent of inducible wall motion abnormalities and the workload/dose [47]. The higher the wall motion score index and the shorter the ischemia-free stress time are, the lower is the survival rate [47] (Fig. 2). As for the prognostic implication of the different pharmacological stress modalities, a similar prognostic value has been reported for dobutamine and dipyridamole testing [49]. Antiischemic therapy heavily modulates the prognostic impact of pharmacological stress echocardiography [59]. Inducible myocardial ischemia in patients on medical therapy identifies the subset of patients at highest risk of death. On the opposite end, the incidence of death in patients with a negative test off therapy is very low. At intermediate risk are those patients with a negative test on medical therapy or a positive test off medical therapy [59] (Fig. 3). The established prognostic stress echo parameters with their relative event rate are shown in Tables 6 and 7.

\section{Stress echo in special subsets of patients Hypertensive patients}

In hypertensive patients CFR may be significantly reduced independent of the presence of significant CAD. CFR impairment reduces the diagnostic value of exercise electrocardiography and nuclear techniques in the

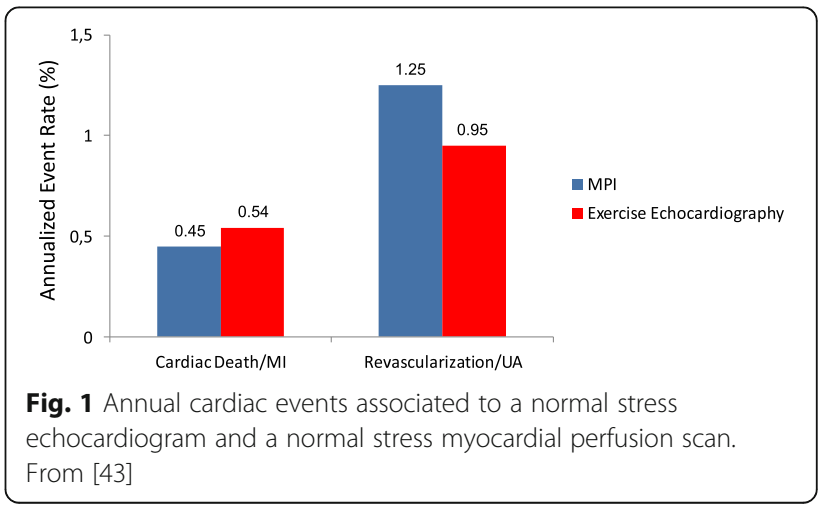



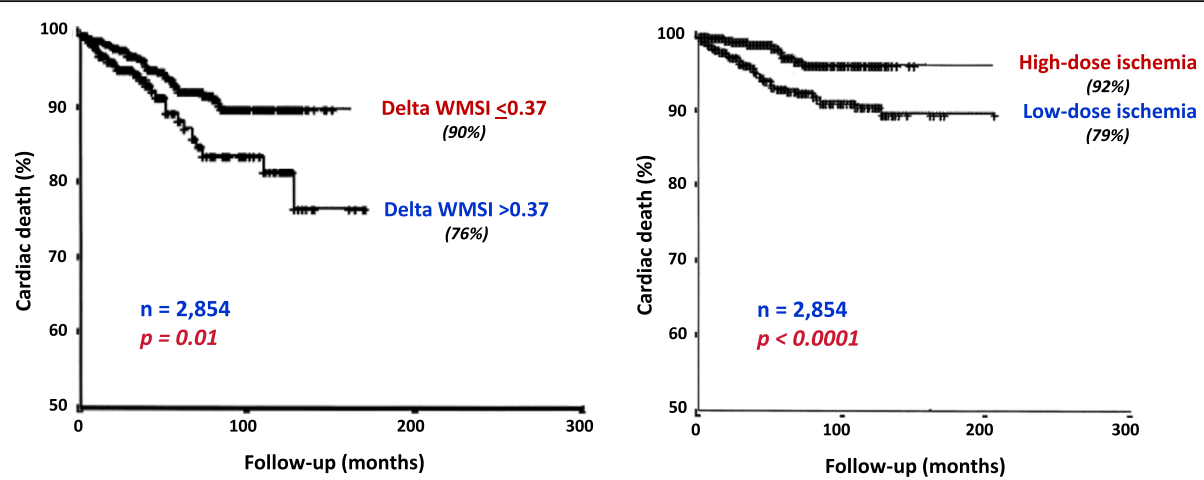

Fig. 2 Kaplan-Meier survival curves (considering cardiac death as end point) in patients with pharmacologic stress echocardiography positive for ischemia stratified on the basis of the extent of ischemia, as expressed by delta wall motion score index (WMSI) set at 0.37 (left panel), and the dose to induce ischemia (left panel). From [47]

hypertensive population, due to high rate of falsepositive responses [10]. In hypertensive patients, stress echocardiography provides superior diagnostic specificity than exercise electrocardiography with no differences in sensitivity [60-62]. Moreover, dipyridamole stress echocardiography is most accurate than perfusion scintigraphy to assess coronary artery disease in patients with exercise electrocardiography positive for ischemia [63]. The prognostic assessment of hypertensive patients is of primary clinical importance since hypertension is associated with almost double risk of developing CAD [64]. Stress-induced wall motion abnormality during pharmacological testing is a strong multivariable predictor of future cardiac events in hypertensive patients with chest pain of unknown origin [65], including those with LV hypertrophy [66], and added prognostic information on top of clinical and exercise electrocardiography [67]. Moreover, the result of test is independently associated with cardiac death in an unselected cohort of hypertensive patients with known or suspected CAD [68].

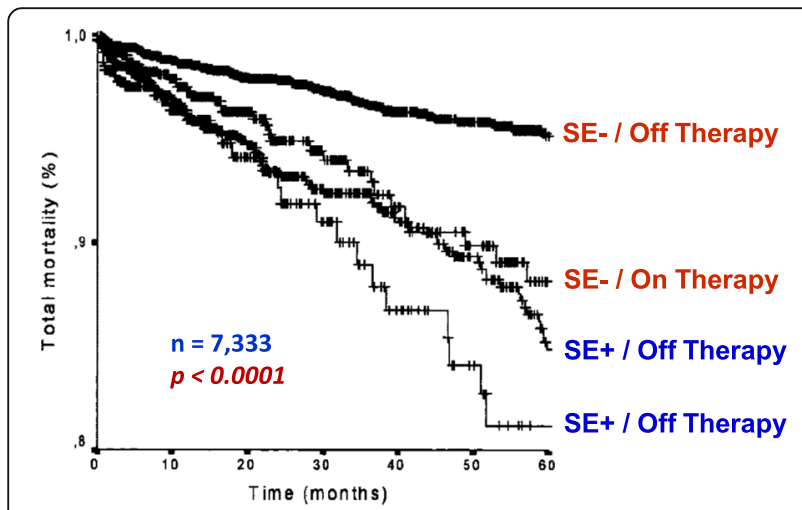

Fig. 3 Kaplan-Meier survival curves (considering total mortality as end point) in patients stratified according to presence (DET +) or absence (DET -) of myocardial ischemia at pharmacological stress echocardiography on and off antianginal medical therapy. From [59]
However, mortality is predicted by inducible ischemia in exercise-tested patients and by the presence of any stress echocardiographic abnormality in those undergoing dobutamine challenge [69]. Inducible ischemia at inotropic stress is also associated with unfavourable outcome in the high-risk population of hypertensive patients unable to exercise [69]. Exercise-induced change in LV ejection fraction proved to be a multivariable predictor of mortality incremental to clinical findings, LV mass index, and resting LV function among hypertensive patients with LV hypertrophy [70]. Finally, echocardiographic LV wall motion abnormalities in adults without overt cardiovascular disease is associated with 2.4 to 3.4 fold higher risks of cardiovascular morbidity and mortality, independent of established risk factors [71]. It has been demonstrated in a large sample of 11.542 patients, that a normal study with any type of stressor is a marker of low risk; however in the hypertensive group the risk is higher [72]. Inducible ischemia at stress echocardiography is an independent predictor of hard cardiac events, and the level of risk is related to the extent of the inducible abnormality as expressed by peak wall motion score index [72] (Fig. 4).

Table 6 Risk stratification for a positive test

\begin{tabular}{lll}
\hline 1-year Risk (hard events) & Intermediate (1-3\% year) & High (>10\% year) \\
\hline Dose/workload & High & Low \\
Resting EF & $>50 \%$ & $<40 \%$ \\
Anti-ischaemic therapy & Off & On \\
Coronary territory & LCX/RCA & LAD \\
Peak WMSI & Low & High \\
Recovery & Fast & Slow \\
Positivity or baseline & Homozonal & Heterozonal \\
dyssynergy & & \\
CFR & $>2.0$ & $<2.0$ \\
\hline
\end{tabular}


Table 7 Risk stratification for a negative test

\begin{tabular}{lll}
\hline 1 -year Risk (hard events) & Very low $(<0.5 \%$ year $)$ & Low $(1-3 \%$ year $)$ \\
\hline Stress & Maximal & Submaximal \\
Resting EF & $>50 \%$ & $<40 \%$ \\
Anti-ischaemic therapy & Off & On \\
CFR & $>2.0$ & $<2.0$ \\
\hline
\end{tabular}

\section{Diabetic patients}

Exercise electrocardiography is of limited value in diabetic patients because exercise capacity is often impaired by peripheral vascular disease, neuropathic disease, and obesity. In addition, test specificity on electrocardiographic criteria is less than ideal due to high prevalence of hypertension and microvascular disease. Stress echocardiography can play a key role in the optimal identification of high risk diabetic patients, also minimizing the economic and biologic costs of diagnostic screening [1]. The coexistence of epicardial coronary artery stenosis with microangiopathy can explain the low specificity of perfusion imaging compared to stress echocardiography in the detection of CAD in asymptomatic and symptomatic diabetic patients [73, 74]. In diabetic patients, stress echocardiography has shown a higher specificity than perfusion imaging but suffers from higher rate of falsepositive results, possibly due to the coexistence of cardiomyopathy in many patients [75]. Risk stratification of diabetic patients is a major objective for the clinical cardiologist, given their increased risk for coronary artery disease [76]. Several studies have addressed the prognostic ability of stratification of non-invasive imaging in patients with and without diabetes. In particular, in patients with overt resting ischemic cardiomyopathy, the presence of myocardial viability recognized by dobutamine stress echocardiography independently predicted improved outcome following revascularization in nondiabetics as well as in diabetic patients following revascularization [77]. Also in unselected patient populations with proven or suspected CAD, a clear refinement of prognosis can be obtained with stress echocardiography, first and foremost on the basis of classical wall motion abnormalities [58, 78-83], which place the patients in a high-risk subset for cardiovascular events. The incremental prognostic information provided by stress echocardiography is highest in patients with intermediate-to-high threshold positive exercise electrocardiography test results [84]. However, in diabetic patients - differently from nondiabetic subjects - a negative test result based solely on wall motion criteria is associated with less benign outcome [58] (Fig. 5). In a study on 2,349 diabetic patients investigated with dobutamine stress echocardiography, the mortality and cardiovascular morbidity were significantly higher in subjects with abnormal or ischemic test results [82]. Also, failure to achieve target heart rate and percentage of ischemic segments, an indicator of the extent of inducible ischemia, were independent predictors and incremental to clinical and rest echocardiographic variables for predicting adverse long-term outcomes [82]. In a more recent study assessing the long-term follow-up of stress echocardiography, dobutamine stress echocardiography provided restricted predictive value of adverse outcome in patients with diabetes who were unable to perform an adequate exercise stress test [83]. The Authors also identified a "warranty" period of the test which provided optimal risk stratification up to 7 years after initial testing. Repeated dobutamine stress echocardiography at that time might add to its prognostic value [83]. In a recent study enrolling a large sample of 14.000 diabetic and nondiabetic patients, stress echocardiography showed that a normal study with any type of stressor is a marker of low risk; however in the diabetic group the risk is higher [85] (Fig. 5). Inducible ischemia at stress echocardiography is an independent predictor of mortality, and the level of risk is related to the extent of the inducible abnormality as expressed by peak wall motion score index. However, the presence of rest wall motion abnormalities is an independent predictor of mortality in both patient groups [85]. Medical therapy at time of testing confers a higher risk of mortality in nondiabetics

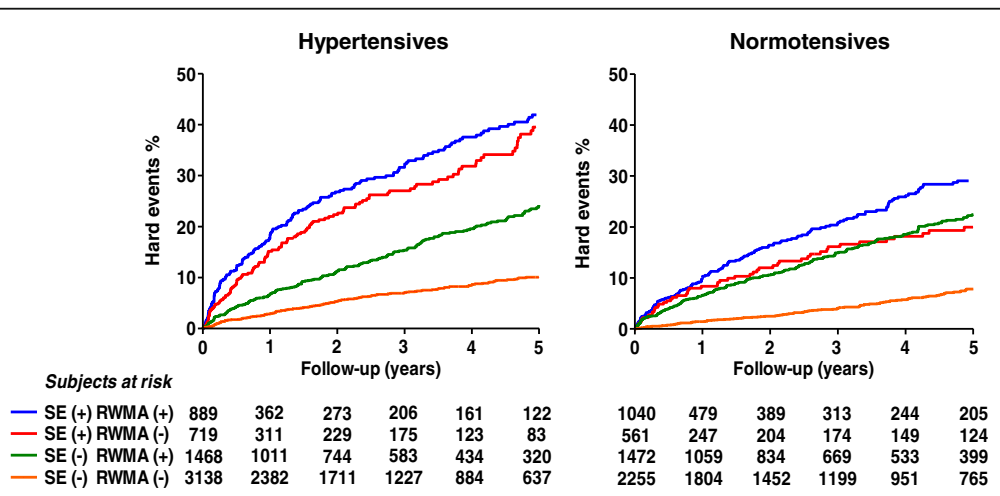

Fig. 4 Hard event rates for hypertensive and normotensive patients separated on the basis of presence (+) or absence (-) of ischemia at stress echocardiography, and presence $(+)$ or absence $(-)$ of resting wall motion abnormality (RWMA). From [72] 


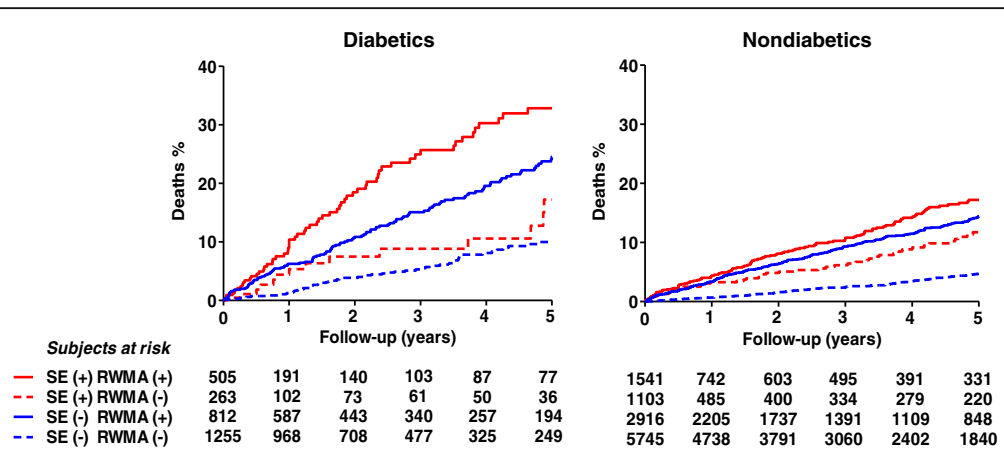

Fig. 5 Mortality for diabetic and nondiabetic patients separated on the basis of presence (+) or absence (-) of ischemia at stress echocardiography, and presence $(+)$ or absence $(-)$ of resting wall motion abnormality (RWMA). From [85]

but did not appear to impact on outcome in the diabetic group [85]. The lack of modulation of stress testing by medical therapy suggest that inducible ischemia is more severe in the diabetic population. Stress myocardial perfusion imaging can be considered a viable alternative to stress echocardiography with the limitation of being less available, more expensive and with potential long-term downstream detrimental effect due to ionizing radiations [86]. Stress myocardial perfusion imaging has been shown to have significant prognostic power for future cardiac events in the symptomatic diabetic population. In a large multicenter study enrolling 4,755 patients (20\% diabetic patients) who underwent exercise of pharmacologic myocardial perfusion imaging for symptomatic CAD, abnormal stress myocardial perfusion imaging was found to be an independent predictor of cardiac events in both diabetic and nondiabetic sample [87]. Moreover, the number of abnormal segments (fixed or ischemic) was related to worse outcome [87] and this is consistent with the stress echocardiographic findings showing an ominous outcome for higher values of wall motion score index.

\section{Women}

The diagnostic specificity of exercise electrocardiography and myocardial perfusion scintigraphy is definitely lower in women than in men. Reduction of coronary flow reserve in syndrome X (mostly affecting female patients), hormonal influences for exercise testing, and breast attenuation for nuclear technique are potential explanations. In contrast, echocardiography combined with exercise or pharmacologic agents provides similar sensitivity but a better specificity as compared to exercise electrocardiography $[88,89]$ and perfusion scintigraphy [90]. In women the prognostic value of stress echocardiography is high, similar to that in men [91]. In patients with chest pain of unknown origin, a normal test is associated with $<1 \%$ event-rate at 3 years of follow-up, while an ischemic test is a strong and independent predictor of future events [92]. Moreover, stress-induced ischemia adds prognostic information on top of clinical and exercise electrocardiography data [93] (Fig. 6). In contrast to ECG stress test and perfusion imaging, stress echocardiography is an "equal opportunity" test, with no difference in diagnostic and prognostic accuracy between males and females. When exercise electrocardiography gives positive or ambiguous results, stress echocardiography is warranted [94]. The choice of an imaging test in this setting should take into account the radiologic burden. Recommendations from the European Society of Cardiology suggest to use non-ionising imaging techniques especially in highly vulnerable subjects such as younger women [87].

\section{Left bundle branch block}

The presence of left bundle branch block makes the electrocardiogram uninterpretable for ischemia and, therefore, a stress imaging is necessary. The abnormal sequence of LV activation determines increased diastolic extravascular resistance, with lower and slower diastolic coronary flow, accounting for the stress-induced defect often observed by perfusion imaging in patients with normal coronary arteries [95]. In spite of the difficulty posed by abnormal wall motion, stress echocardiography is the

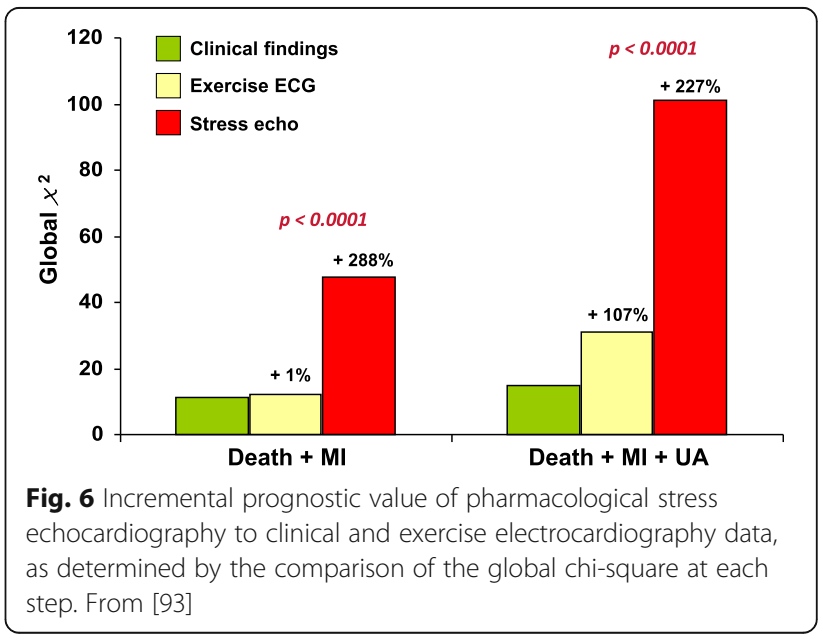


best diagnostic option in patients with left bundle branch block. It is more specific than perfusion imaging [95], and its sensitivity is good, albeit reduced in the left anterior descending territory in the presence of a dyskinetic septum in resting conditions [96]. Moreover, myocardial ischemia by pharmacologic stress echocardiography has a strong and independent power in the prediction of future hard events in left bundle branch block patients, providing a prognostic contribution that is incremental to that of clinical and resting echo findings in the group without previous myocardial infarction [97].

\section{Noncardiac vascular surgery}

Perioperative ischemia is a frequent event in patients undergoing major noncardiac vascular or general surgery and coronary disease is known to be the leading cause of perioperative mortality and morbidity following vascular and general surgery $[98,99]$. The diagnostic/therapeutic corollary of these considerations is that CAD - and therefore the perioperative risk - in these patients has to be identified in an effective way preoperatively. This is not feasible in an accurate way with either clinical scores (such as Detsky's or Goldman's score) or rest echocardiography, only. The updated ESC guidelines recommend an imaging stress testing before high-risk surgery in patients with more than two clinical risk factors and poor functional capacity (Class I, Evidence C) [98]. Pharmacological stress echocardiography has been proven to be an effective tool for risk stratification when compared to perfusion scintigraphy [100-112]. Its advantages are due to lower costs and the lack of ionising radiations and in this particular setting it is more feasible than exercise stress echo. The experience with either dipyridamole and dobutamine indicates that these tests have a very high and comparable negative predictive value (between 90 and 100\%) [113]. A negative test result is associated with a very low incidence of cardiac events allowing a safe surgical procedure [113-115]. The positive predictive value is relatively low (between 25 and 45\%): this means that the post-surgical probability of events is low. Stress echocardiography shows a comparable diagnostic and prognostic accuracy when compared to perfusion imaging. The risk stratification capability is high for perioperative events and also remains excellent for long-term follow-up [116, 117]. Other techniques such as CMR and CCTA are available but the evidence is too scant to be recommended. Moreover, costs and risks should be weighed in the model of stratification and high tech imaging techniques do not seem to be adequate for a large scale assessment. Stress testing should be used in the diagnostic algorithm only when its result might influence peri-operative management and outcome. To date, it appears reasonable to perform coronary revascularization before peripheral vascular surgery in the presence of a markedly positive result of stress echocardiography in which standard medical therapy appears insufficient to prevent a peri-operative cardiac event. A more conservative approach - with watchful cardiological surveillance coupled with pharmacological cardioprotection with $\beta$-blockers - can be adopted in patients with less severe ischemic responses during stress [99]. Concerns have been raised on the initiation of betablockers before surgery without titration (to avoid hypotension and bradychardia) and in low risk patients [118]. Interestingly, clearly inappropriate indications for preoperative risk stratification before noncardiac surgery (intermediate risk surgery in patients with good exercise capacity, and low risk surgery) account for $25 \%$ of all inappropriate testing in large-volume stress echocardiography laboratories [119-122], and therefore this field provides a key opportunity for quality improvement and targeted educational programs to achieve measurable improvements in results.

\section{Myocardial viability}

The stress echo sign of myocardial viability is a stressinduced improvement of function during low levels of stress in a region that is abnormal at rest. By far, the widest experience is available with low-dose dobutamine stress echocardiography [123-125] the preferred stressor for assessing myocardial viability. However, it is also possible to assess the presence of myocardial viability using low-dose dipyridamole [126-128] or low-level exercise [129] or enoximone [130, 131].

In patients with dysfunctional but viable myocardium, regional function can be improved by the inotropic effect of low-dose $(5-10 \mu \mathrm{g} / \mathrm{kg} / \mathrm{min}$.) dobutamine stress echocardiography [11]. Sensitivity and specificity of lowdose dobutamine test are, respectively, 86 and 90\% for predicting spontaneous functional recovery after an acute myocardial infarction (stunning) [123], and 84 and $81 \%$ for predicting functional recovery following revascularization in patients with chronic CAD (hibernation) [124]. Compared to nuclear techniques, dobutamine stress echocardiography has lower sensitivity, but higher specificity, with similar overall accuracy regarding recovery of function $[124,125]$. In quantitative terms, contractile reserve evidenced by a positive dobutamine requires at least $50 \%$ viable myocytes in a given segment, whereas scintigraphic methods also identify segments with less viable myocytes [132]. Minor levels of viability, characterized by scintigraphic positivity and dobutamine echocardiography negativity, are often unable to translate into functional recovery. This explains the different diagnostic performance of the two methods.

Observational studies have indeed suggested that patients with ischaemic LV dysfunction and a significant amount of viable myocardium (at least five segments or a wall motion score index $>0.25$ ) [133-142] have lower 
perioperative mortality, greater improvements in regional and global LV function, fewer heart failure symptoms, and improved long-term survival after revascularization than patients with large areas of non-viable myocardium. On the other hand, viability has no impact on survival in patients with preserved or just moderately depressed LV function; in this case, it can rather predict the occurrence of acute coronary events, representing a substrate for unstable ischemic episodes [50].

Viability at dobutamine stress echocardiography predicts an improved outcome following revascularization both in diabetic and nondiabetic patients with ischemic cardiomyopathy [77]. No measurable performance difference for predicting revascularization benefit between stress echocardiography and nuclear methods has been reported [141]. The documentation of viable myocardium at dobutamine test also predicts responders to resynchronization therapy: patients with contractile reserve show a favourable clinical and reverse LV remodelling response to resynchronization therapy [143, 144].

\section{Coronary flow reserve}

In recent years the evaluation of CFR by combining transthoracic Doppler assessment of coronary flow velocities with vasodilator stress has entered the echo lab as an effective modality for both diagnostic and prognostic purposes [1]. The use of CFR as a stand-alone diagnostic criterion suffers from two main limitations. In fact, only left anterior descending artery is sampled with very high success rate. Moreover, CFR cannot distinguish between microvascular and macrovascular coronary disease [1]. Therefore it is much more interesting to assess the additional diagnostic value over conventional wall motion analysis. CFR of left anterior descending artery is a strong and independent indicator of mortality, conferring additional prognostic value over wall motion analysis in patients with known or suspected CAD [145] (Fig. 7). A negative result on stress echocardiography with a normal CFR confers an annual risk of death $<1 \%$ [145] (Fig. 7). Moreover, CFR yields useful prognostic information in several clinical subsets, such as diabetics with unchanged wall motion during stress [146] (Fig. 8), hypertensives [147], patients with intermediate coronary stenosis [148], left bundle branch block [149], and normal or near normal coronary arteries [147, 149-151] (Fig. 9). A CFR $<2.0$ is an additional parameter of ischemia severity in the risk stratification of the stress echocardiographic response whereas patients with a negative test for wall motion criteria and CFR $>2.0$ during dipyridamole stress echocardiography have a favorable outcome. Similar results have been obtained when perfusion imaging was added to wall motion analysis [152] (Fig. 10). In diabetic patients, a normal CFR is associated with tighter glycemic control [153] and better

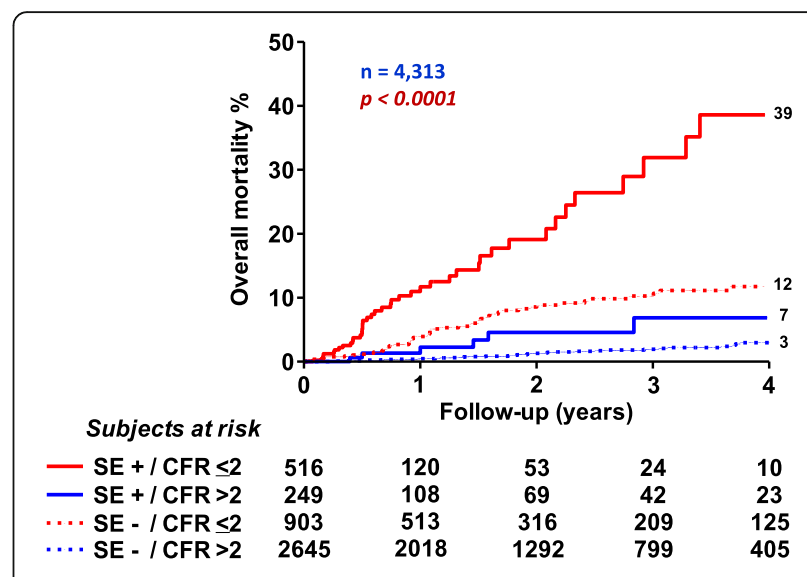

Fig. 7 Mortality rates in patients with known or suspected coronary artery disease separated on the basis of presence $(+)$ or absence $(-)$ of ischemia at stress echocardiography (SE) and coronary flow reserve (CFR) of left anterior descending artery $>2$ or $\leq 2$. From [145]

long-term event-free survival both considering unselected patients $[146,154]$ and patients with angiographically normal coronary arteries [151] (Fig. 9). Within the subset of chest pain hypertensive patients with normal coronary arteries an effective risk stratification has been obtained according to quartilies of CFR [147] (Fig. 9). Anti-ischemic medication at the time of testing does not modulate the prognostic value of CFR, which is per se a prognostic marker independent of therapy [155] (Fig. 11). Specialist guidelines endorse an extensive application of CFR in the stress echo lab, suggesting that "whenever possible, it is recommended to perform dual imaging (flow and function) vasodilator stress echo [11].

\section{The shift from qualitative to quantitative reading}

The search for a totally operator-independent quantitative tool for stress echocardiography is still on-going. The state-of-the art diagnosis of ischaemia in stress echocardiography remains the eyeballing interpretation of regional wall motion in black and white cine-loops. Several ultrasound technologies have been proposed in the last few years in order to overcome the qualitative interpretation of stress echocardiography: tissue characterization, Tissue Doppler imaging, strain rate and speckle tracking. However, none of these technologies has a place in the routine clinical practice of stress echo. EACVI/ASE Guidelines do not recommend its rotine clinical use unless some major limitations and pitfalls are solved [156]: "While the published research provides the evidence basis for potential clinical applications of these techniques in multiple clinical scenarios, the writing group believes that in the majority of areas, this methodology is not yet ready for routine clinical use. The consensus is that: (1) additional testing is needed in multicenter settings to better establish the diagnostic accuracy of the 


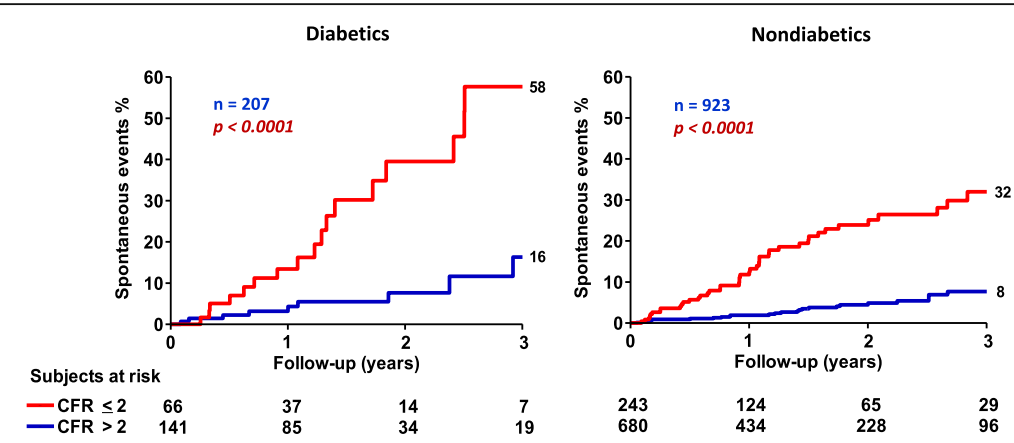

Fig. 8 Hard event rates in diabetic and nondiabetic patients with stress echo negative for ischemia separated on the basis of coronary flow reserve (CFR) of left anterior descending artery $>2$ or $\leq 2$. From [146]

different parameters and their reproducibility in various disease states, (2) standardization is needed for what should be measured and how measurements should be performed, and (3) standardization among manufacturers is essential, as clinicians should be able to interpret data generated by different equipment irrespective of vendor". It is conceivable that once the inter-vendor comparability is solved, speckle tracking would play a relevant role in determining forms of subtle LV dysfunction and minor degrees of subendocardial ischemia, otherwise non detectable with wall motion analysis. Real-time three dimensional echocardiography has also proven to be accurate and reproducible, but it remains time consuming and frame rates are too low for stress echocardiography [1]. The EACVI/ASE consensus document states that 3D stress transthoracic echocardiography holds promise for incorporation into clinical practice in the future [157]. Its advantages are: 1 . Better visualization of the LV apex, which is frequently foreshortened on standard 2D apical images; 2. Rapid acquisition of peak stress images before the heart declines in recovery; and 3. Evaluation of multiple segments from different planes from a single data set.

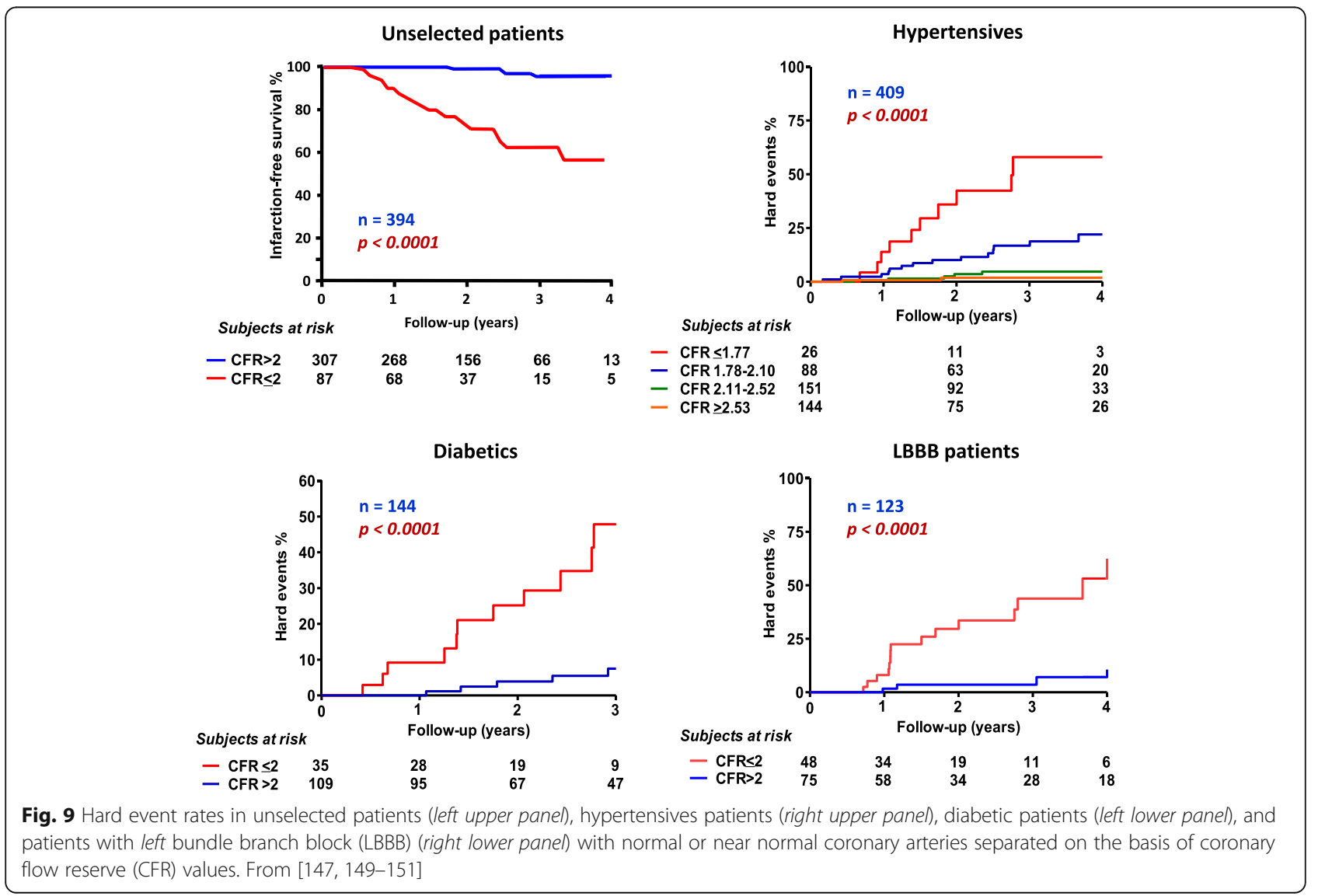




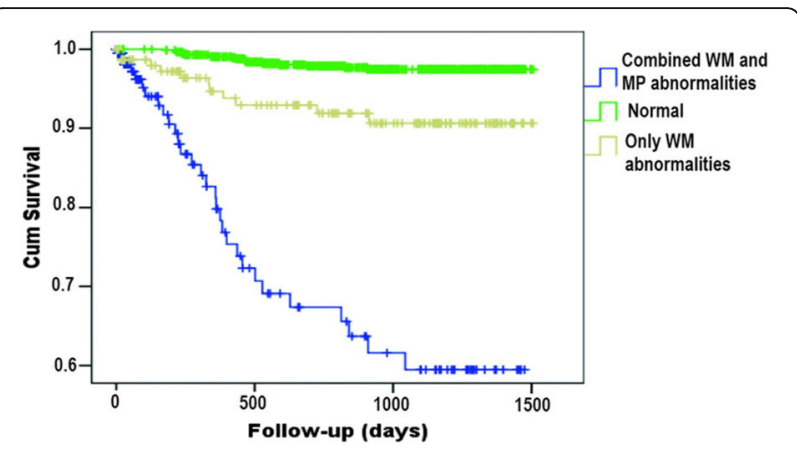

Fig. 10 Kaplan-Meier curves based on the combination of presence or absence of wall motion (WM) abnormalities and myocardial perfusion (MP) abnormalities. From [152]

Disadvantages include lower spatial resolution and lower frame rates [157].

Myocardial contrast echocardiography (MCE) has undergone rapid development in the past 5 years. With the advent of newer-generation microbubbles, intravenous agents can now be used to both improve endocardial border delineation and, detect myocardial perfusion. Along with the development of microbubbles which consistently opacify the left heart from a venous injection, newer imaging modalities have evolved which permit the detection of myocardial perfusion abnormalities in real time, at frame rates which are greater than $25 \mathrm{~Hz}$. In order to accurately detect wall motion abnormalities during stress echocardiography, a clear definition of endocardial borders is of particularly importance. The approved indication for the use of contrast echocardiography currently lies in improving endocardial border delineation in patients in whom adequate imaging is difficult or suboptimal [158].

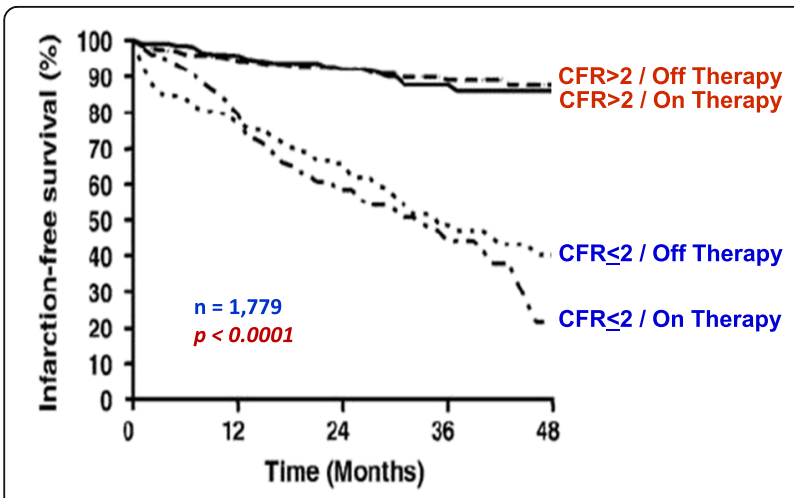

Fig. 11 Kaplan-Meier survival curves (considering hard events as end point) in patients stratified on the basis of coronary flow reserve (CFR) of left anterior descending artery $>2$ or $\leq 2$ on and off antianginal medical therapy. From [155]

\section{Safety of pharmacologic stress echocardiography}

Stress echocardiography is a safe technique but minor, limiting, side effects may preclude the achievement of maximal testing. Safety profile of stress echocardiography depends on the stressor used. Exercise is the safest stressor as shown in large samples with the long - lasting experience of ECG stress test [159]. Stress echo registries collecting data on thousands of patients [160-163] have shown that exercise is the safest test. Death has an incidence rate of 1 in 10,000 tests. Major life-threatening effects (myocardial infarction, ventricular fibrillation, sustained ventricular tachycardia, stroke) occur in about 1 in 6000 patients with exercise in the international stress echocardiography registry - fivefold less than with dipyridamole echocardiography and tenfold less than with dobutamine echocardiography. Exercise, whenever feasible, should be the preferred stressor due to its safety profile. Exercise is safer than pharmacological stress echocardiography and dipyridamole is safer than dobutamine. Not all stress tests carry the same risk of major adverse reactions and the choice of one test over the other should take into account the safety profile.

\section{Conclusions}

Stress echocardiography is an established technique for the assessment of known or suspected CAD. It is recommended in all major cardiology guidelines in several clinical settings. However, its status of established technology, should prompt its clinical use as the preferred non-invasive imaging technique due to its low cost, wide availability and lack of radiation exposure. Though these unique features, an utilization gap remains with nuclear techniques percevied as more objective in the face of a comparable diagnostic and prognostic accuracy. The flexible use of stressors (exercise, inotropic and vasodilating) maximazes the feasibility, avoids specific contra-indications and allows tailoring the exam on each individual patient. A paradigm shift will occur when from a highly expertise qualitative reading stress echocardiography will move to a quantitative approach that would make it easier also for less skilled readers. Technological premises are there at hand but they have not reached a fullblown status to be used on a routine clinical basis. Society recommendantions and guidelines are mostly based on consensus and level of evidence C. The gap of knowledge should be filled with prospective large scale studies to support evidence-based treatment strategies. Eugenio Picano and Patricia Pellikka, two pioneers of the technique invite the scientific community to design "prospective large scale and (when possible) randomised (medical vs. interventional treatment) outcome studies to support more evidence-based rather than consensus-based strategies, based on stress echo results, in CAD and non-CAD patients" [164]. 


\section{Abbreviations}

ASE: American Society of Echocardiography; CAD: Coronary artery disease: CFR: Coronary flow reserve; EACVI: European Association of Cardiovascular Imaging; ESC: European Society of Cardiology; LV: Left ventricle

\section{Funding}

No funding was needed to conduct the study.

\section{Availability of data and materials}

Data sharing not applicable to this article as no datasets were generated or analysed during the current study.

\section{Authors' contribution}

RS Drafted the manuscript, reviewed literature; LC contributed with relevant criticism to the final draft of the manuscript. Both authors read and approved the final manuscript.

\section{Competing interests}

RS is the Editor-in-Chief of Cardiovascular but the manuscript was independently handled by an Associate Editor.

\section{Consent for publication}

Not applicable.

\section{Ethics approval and consent to participate}

The present manuscript is a review on stress echocardiography and there is no need to submit the study to ethics committee.

\section{Publisher's Note}

Springer Nature remains neutral with regard to jurisdictional claims in published maps and institutional affiliations.

\section{Author details}

${ }^{1}$ CNR, Institute of Clinical Physiology, Via G. Moruzzi, 1, 56124 Pisa, Italy.

${ }^{2}$ Department of Cardiology, San Luca Hospital, Lucca, Italy.

\section{Received: 22 December 2016 Accepted: 15 March 2017} Published online: 21 March 2017

\section{References}

1. Picano E. Stress echocardiography. 6th ed. Heidelberg: Springer Verlag; 2015.

2. Picano E. Dipyridamole-echocardiography test: historical background and physiologic basis. Eur Heart J. 1989:10:365-76.

3. Ross Jr J. Mechanisms of regional ischaemia and antianginal drug action during exercise. Prog Cardiovasc Dis. 1989:31:455-66.

4. Gallagher KP, Matsuzaki M, Koziol JA, Kemper WS, Ross Jr J. Regional myocardial perfusion and wall thickening during ischaemia in conscious dogs. Am J Physiol. 1984;247:H727-738.

5. Picano E, Lattanzi F, Masini M, Distante A, L'Abbate A. Usefulness of a high-dose dipyridamole-echocardiography test for diagnosis of syndrome $X$ Am J Cardiol. 1987;60:508-12.

6. Kaski JC, Rosano GM, Collins P, Nihoyannopoulos P, Maseri A, Poole-Wilson PA. Cardiac syndrome $X$ : clinical characteristics and left ventricular function. Long-term follow-up study. J Am Coll Cardiol. 1995;25:807-14.

7. Palinkas A, Toth E, Amyot R, Rigo F, Venneri L, Picano E. The value of ECG and echocardiography during stress testing for identifying systemic endothelial dysfunction and epicardial artery stenosis. Eur Heart J. 2002;23:1587-95.

8. Camici PG, Gistri R, Lorenzoni R, Sorace O, Michelassi C, Bongiorni MG, Salvadori PA, L'Abbate A. Coronary reserve and exercise ECG in patients with chest pain and normal coronary angiograms. Circulation. 1992;86:179-86.

9. Nihoyannopoulos P, Kaski J-C, Crake T, Maseri A. Absence of myocardial dysfunction during stress in patients with syndrome X. J Am Coll Cardiol. 1991:18:1463-70.

10. Picano E, Palinkas A, Amyot R. Diagnosis of myocardial ischaemia in hypertensive patients. J Hypertens. 2001;19:1177-83.

11. Sicari R, Nihoyannopoulos P, Evangelista A, Kasprzak J, Lancellotti P, Poldermans D, Voigt J, Zamorano JL. Stress echocardiography expert consensus statement. Eur J Echocardiogr. 2008;9:415-37.

12. Peteiro J, Bouzas-Mosquera A, Estevez R, Pazos P, Piñeiro M, Castro-Beiras A Head-to-head comparison of peak supine bicycle exercise echocardiography and treadmill exercise echocardiography at peak and at post-exercise for thedetection of coronary artery disease. J Am Soc Echocardiogr. 2012;25:319-26.

13. Piérard LA. Echocardiographic monitoring throughout exercise better than the post-treadmill approach? J Am Coll Cardiol. 2007:50:1864-6.

14. Berthe C, Pierard LA, Hiernaux M, Trotteur G, Lempereur P, Carlier J, Kulbertus HE. Predicting the extent and location of coronary artery disease in acute myocardial infarction by echocardiography during dobutamine infusion. Am J Cardiol. 1986:58:1167-72

15. McNeill AJ, Fioretti PM, El-Said SM, Salustri A, Forster T, Roelandt JR. Enhanced sensitivity for detection of coronary artery disease by addition of atropine to dobutamine stress echocardiography. Am J Cardiol. 1992;70:41-6.

16. Picano E, Simonetti I, Masini M, Marzilli M, Lattanzi F, Distante A, De Nes M, L'Abbate A. Transient myocardial dysfunction during pharmacologic vasodilation as an index of reduced coronary reserve: a coronary hemodynamic and echocardiographic study. J Am Coll Cardiol. 1986;8(1):84-90.

17. Picano E, Lattanzi F, Masini M, Distante A, L'Abbate A. High dose dipyridamoleechocardiography test in effort angina pectoris. J Am Coll Cardiol. 1986:8:848-54.

18. Picano E, Pingitore A, Conti U, Kozàkovà M, Boem A, Cabani E, Ciuti M, Distante A, L'Abbate A. Enhanced sensitivity for detection of coronary artery disease by addition of atropine to dipyridamole echocardiography. Eur Heart J. 1993;14:1216-22.

19. Dal Porto R, Faletra F, Picano E, Pirelli S, Moreo A, Varga A. Safety, feasibility, and diagnostic accuracy of accelerated high-dose dipyridamole stress echocardiography. Am J Cardiol. 2001;87:520-4.

20. Zoghbi WA, Cheirif J, Kleiman NS, Verani MS, Trakhtenbroit A. Diagnosis ofischemic heart disease with adenosine echocardiography. J Am Coll Cardiol. 1991;18:1271-9.

21. Picano E, Alaimo A, Chubuchny V, Plonska E, Baldo V, Baldini U, Pauletti M, Perticucci R, Fonseca L, Villarraga HR, Emanuelli C, Miracapillo G, Hoffmann E, De Nes M. Noninvasive pacemaker stress echocardiography for diagnosis of coronary artery disease: a multicenter study. J Am Coll Cardiol. 2002;40: 1305-10.

22. Task Force Members, Montalescot G, Sechtem U, Achenbach S, Andreotti F, Arden C, Budaj A, Bugiardini R, Crea F, Cuisset T, Di Mario C, Ferreira JR, Gersh BJ, Gitt AK, Hulot JS, Marx N, Opie LH, Pfisterer M, Prescott E, Ruschitzka F, Sabaté M, Senior R, Taggart DP, van der Wall EE, Vrints CJ, ESC Committee for Practice Guidelines, Zamorano JL, Achenbach S, Baumgartner H, Bax JJ, Bueno H, Dean V, Deaton C, Erol C, Fagard R, Ferrari R, Hasdai D, Hoes AW, Kirchhof P, Knuuti J, Kolh P, Lancellotti P, Linhart A, Nihoyannopoulos P, Piepoli MF, Ponikowski P, Sirnes PA, Tamargo JL, Tendera M, Torbicki A, Wijns W, Windecker S, Document R, Knuuti J, Valgimigli M, Bueno H, Claeys MJ, Donner-Banzhoff N, Erol C, Frank H, Funck-Brentano C, Gaemperli O, Gonzalez-Juanatey JR, Hamilos M, Hasdai D, Husted S, James SK, Kervinen K, Kolh P, Kristensen SD, Lancellotti P, Maggioni AP, Piepoli MF, Pries AR, Romeo F, Rydén L, Simoons ML, Sirnes PA, Steg PG, Timmis A, Wijns W, Windecker S, Yildirir A, Zamorano JL. 2013 ESC guidelines on the management of stable coronary artery disease: the Task Force on the management of stable coronary artery disease of the European Society of Cardiology. Eur Heart J. 2013;34:2949-3003.

23. Heijenbrok-Kal MH, Fleischmann KE, Hunink MG. Stress echocardiography, stress single-photon-emission computed tomography and electron beam computed tomography for the assessment of coronary artery disease: a meta-analysis of diagnostic performance. Am Heart J. 2007;154:415-23.

24. Picano E, Molinaro S, Pasanisi E. The diagnostic accuracy of pharmacological stress echocardiography for the assessment of coronary artery disease: a meta-analysis. Cardiovasc Ultrasound. 2008;6:30.

25. Severi S, Picano E, Michelassi C, Lattanzi F, Landi P, Distante A, L'Abbate A. Diagnostic and prognostic value of dipyridamole echocardiography in patients with suspected coronary artery disease. Comparison with exercise electrocardiography. Circulation. 1994:89:1160-73.

26. Lattanzi F, Picano E, Bolognese L, Piccinino C, Sarasso G, Orlandini A, L'Abbate A. Inhibition of dipyridamole-induced ischemia by antianginal therapy in humans. Correlation with exercise electrocardiography. Circulation. 1991;83:1256-62

27. Sawada SG, Ryan T, Conley M, Corya BC, Feigenbaum H, Armstrong W. Prognostic value of a normal exercise echocardiogram. Am Heart J. 1990;120:49-55.

28. Elhendy A, Shub C, McCully RB, Mahoney DW, Burger KN, Pellikka PA. Exercise echocardiography for the prognostic stratification of patients with low pretest probability of coronary artery disease. Am J Med. 2001;111:18-23. 
29. Marwick TH, Case C, Vasey C, Allen S, Short L, Thomas JD. Prediction of mortality by exercise echocardiography: a strategy for combination with the duke treadmill score. Circulation. 2001;103:2566-71.

30. Arruda-Olson AM, Juracan EM, Mahoney DW, McCully RB, Roger VL, Pellikka PA. Prognostic value of exercise echocardiography in 5,798 patients: is there a gender difference? J Am Coll Cardiol. 2002;39:625-31.

31. McCully RB, Roger VL, Mahoney DW, Burger KN, Click RL, Seward JB, et al. Outcome after abnormal exercise echocardiography for patients with good exercise capacity: prognostic importance of the extent and severity of exerciserelated left ventricular dysfunction. J Am Coll Cardiol. 2002;39:1345-52.

32. Jaarsma W, Visser C, Funke KA. Usefulness of two-dimensional exercise echocardiography shortly after myocardial infarction. Am J Cardiol. 1986:57:86-90.

33. Applegate RJ, Dell'italia $L J$, Crawford MH. Usefulness of twodimensional echocardiography during low-level exercise testing early after uncomplicated myocardial infarction. Am J Cardiol. 1987;60:10-4.

34. Ryan T, Armstrong WF, O'Donnel JA, Feigenbaum H. Risk stratification following acute myocardial infarction during exercise two-dimensional echocardiography. Am Heart J. 1987;114:1305-16.

35. Quintana M, Lindvall K, Ryden L, Brolund F. Prognostic value of predischarge exercise stress echocardiography after acute myocardial infarction. Am J Cardiol. 1995;76:1115-21.

36. Hoque A, Maaieh M, Longaker RA, Stoddard MF. Exercise echocardiography and thallium-201 single-photon emission computed tomography stress test for 5- and 10-year prognosis of mortality and specific cardiac events. J Am Soc Echocardiogr. 2002;15:1326-34.

37. Elhendy A, Mahoney DW, Khandheria BK, Paterick TE, Burger KN, Pellikka PA. Prognostic significance of the location of wall motion abnormalities during exercise echocardiography. J Am Coll Cardiol. 2002;40:1623-9.

38. Mazur W, Rivera JM, Khoury AF, Basu AG, Perez-Verdia A, Marks GF, Chang SM, Olmos L, Quiñones MA, Zoghbi WA. Prognostic value of exercise echocardiography: validation of a new risk index combining echocardiographic, treadmill, and exercise electrocardiographic parameters. J Am Soc Echocardiogr. 2003;16:318-25.

39. Marwick TH, Case C, Short L, Thomas JD. Prediction of mortality in patients without angina: use of an exercise score and exercise echocardiography. Eur Heart J. 2003;24:1223-30.

40. Peteiro J, Monserrat L, Vazquez E, Perez R, Garrido I, Vazquez N, Castro-Beiras A. Comparison of exercise echocardiography to exercise electrocardiographic testing added to echocardiography at rest for risk stratification after uncomplicated acute myocardial infarction. Am J Cardiol. 2003;92:373-6.

41. Elhendy A, Mahoney DW, Burger KN, McCully RB, Pellikka PA. Prognostic value of exercise echocardiography in patients with classic angina pectoris. Am J Cardiol. 2004;94:559-63.

42. Garrido IP, Peteiro J, García-Lara J, Montserrat L, Aldama G, VázquezRodríguez JM, Alvarez N, Castro-Beiras A. Prognostic value of exercise echocardiography in patients with diabetes mellitus and known or suspected coronary artery disease. Am J Cardiol. 2005;96:9-12.

43. Metz LD, Beattie M, Hom R, Redberg RF, Grady D, Fleischmann KE. The prognostic value of normal exercise myocardial perfusion imaging and exercise echocardiography: a meta-analysis. J Am Coll Cardiol. 2007;49:227-37.

44. Mazeika PK, Nadazdin A, Oakley CM. Prognostic value of dobutamine echocardiography in patients with high pretest likelihood of coronary artery disease. Am J Cardiol. 1993;71:33-9.

45. Poldermans D, Fioretti PM, Boersma E, Cornel JH, Borst F, Vermeulen EG, Arnese M, el-Hendy A, Roelandt JR. Dobutamine-atropine stress echocardiography and clinical data for predicting late cardiac events in patients with suspected coronary artery disease. Am J Med. 1994;97:119-25.

46. Marwick TH, Case C, Sawada S, Rimmerman C, Brenneman P, Kovacs R, Short L, Lauer M. Prediction of mortality using dobutamine echocardiography. J Am Coll Cardiol. 2001;37:754-60.

47. Sicari R, Pasanisi E, Venneri L, Landi P, Cortigiani L, Picano E, Echo Persantine International Cooperative (EPIC) Study Group; Echo Dobutamine International Cooperative (EDIC) Study Group. Stress echo results predict mortality: a large scale multicenter prospective international study. J Am Coll Cardiol. 2003;41:589-5895.

48. Carlos ME, Smart SC, Wynsen JC, Sagar KB. Dobutamine stress echocardiography for risk stratication after myocardial infarction. Circulation. 1997;18:1402-10.

49. Pingitore A, Picano E, Varga A, Gigli G, Cortigiani L, Previtali M, Minardi G, Quarta Colosso M, Lowenstein J, Mathias Jr W, Landi P. Prognostic value of pharmacological stress echocardiography in patients with known or suspected coronary artery disease: a prospective, large scale, multicenter, head-to-head comparison between dipyridamole and dobutamine test. J Am Coll Cardiol. 1999;34:1769-77.

50. Sicari R, Picano E, Landi P, Pingitore A, Bigi R, Coletta C, Heyman J, Casazza F. Previtali M, Mathias Jr W, Dodi C, Minardi G, Lowenstein J, Garyfallidis X, Cortigiani $\mathrm{L}$, Morales MA, Raciti M. Prognostic value of dobutamine-atropine stress echocardiography early after acute myocardial infarction. Echo Dobutamine International Cooperative (EDIC) Study. J Am Coll Cardiol. 1997;29:254-60.

51. Poldermans D, Fioretti PM, Boersma E, Bax JJ, Thomson IR, Roelandt JR, Simoons ML. Long-term prognostic value of dobutamine-atropine stress echocardiography in 1737 patients with known or suspected coronary artery disease: a single-center experience. Circulation. 1999;99:757-562.

52. Previtali M, Fetiveau R, Lanzarini $L$, Cavalotti C, Klersy C. Prognostic value of myocardial viability and ischemia detected by dobutamine stress echocardiography early after acute myocardial infarction treated with thrombolysis. J Am Coll Cardiol. 1998;32:380-6.

53. Picano E, Severi S, Michelassi C, Lattanzi F, Masini M, Orsini E, Distante A, L'Abbate A. Prognostic importance of dipyridamole-echocardiography test in coronary artery disease. Circulation. 1989;80:450-7.

54. Picano E, Landi P, Bolognese L, Chiarandà G, Chiarella F, Seveso G, Sclavo MG, Gandolfo N, Previtali M, Orlandini A. Prognostic value of dipyridamole echocardiography early after uncomplicated myocardial infarction: a largescale, multicenter trial. The EPIC Study Group. Am J Med. 1993;95:608-18.

55. van Daele ME, Mcneill AJ, Fioretti PM, Salustri A, Pozzoli MM, el-Said ES, Reijs AE, Mcfalls EO, Slagboom T, Roelandt JR. Prognostic value of dipyridamole sestamibi single-photon emission computed tomography and dipyridamole stress echocardiography for new cardiac events after an uncomplicated myocardial infarction. J Am Soc Echocardiogr. 1994;7:370-80.

56. Neskovic AN, Popovic AD, Babic R, Marinkovic J, Obradovic V. Positive highdose dipyridamole echocardiography test after acute myocardial infarction is an excellent predictor of cardiac events. Am Heart J. 1995;129:31-9.

57. Sicari R, Landi P, Picano E, Pirelli S, Chiaranda G, Previtali M, Seveso G, Gandolfo N, Margaria F, Magaia O, Minardi G, Mathias W, EPIC (Echo Persantine International Cooperative); EDIC (Echo Dobutamine International Cooperative) Study Group. Exercise-electrocardiography and/or pharmacological stress echocardiography for non-invasive risk stratication early after uncomplicated myocardial infarction.A prospective international large scale multicentre study. Eur Heart J. 2002;23:1030-7.

58. Cortigiani L, Bigi R, Sicari R, Landi P, Bovenzi F, Picano E. Prognostic value of pharmacological stress echocardiography in diabetic and nondiabetic patients with known or suspected coronary artery disease. J Am Coll Cardiol. 2006;47:605-10.

59. Sicari R, Cortigiani L, Bigi R, Landi P, Raciti M, Picano E. The prognostic value of pharmacologic stress echo is affected by concomitant anti-ischemic therapy at the time of testing. Circulation. 2004;109:1428-31.

60. Picano E, Lucarini AR, Lattanzi F, Distante A, Di Legge V, Salvetti A, L'Abbate A. Dipyridamole-echocardiography test in essential hypertensives with chest pain. Hypertension. 1988;12:238-43.

61. Cortigiani L, Bigi R, Rigo F, Landi P, Baldini U, Mariani PR, Picano E. Diagnostic value of exercise electrocardiography and dipyridamole stress echocardiography in hypertensive and normotensive chest pain patients with right bundle branch block. J Hypertens. 2003;21:2189-94.

62. Senior R, Basu S, Handler C, Raftery EB, Lahiri A. Diagnostic accuracy of dobutamine stress echocardiography for detection of coronary heart disease in hypertensive patients. Eur Heart J. 1996;17:289-95.

63. Astarita C, Palinkas A, Nicolai E, Maresca FS, Varga A, Picano E. Dipyridamoleatropine stress echocardiography versus exercise SPECT scintigraphy for detection of coronary artery disease in hypertensives with positive exercise test. J Hypertens. 2001;19:495-502.

64. Mancia G, De Backer G, Dominiczak A, Cifkova R, Fagard R, Germano G, Grassi G, Heagerty AM, Kjeldsen SE, Laurent S, Narkiewicz K, Ruilope L, Rynkiewicz A, Schmieder RE, Boudier HA, Zanchetti A, Vahanian A, Camm J, De Caterina R, Dean V, Dickstein K, Filippatos G, Funck-Brentano C, Hellemans I, Kristensen SD, McGregor K, Sechtem U, Silber S, Tendera M, Widimsky P, Zamorano JL, Erdine S, Kiowski W, Agabiti-Rosei E, Ambrosioni E, Lindholm LH, Viigimaa M, Adamopoulos S, Agabiti-Rosei E, Ambrosioni E, Bertomeu V, Clement D, Erdine S, Farsang C, Gaita D, Lip G, Mallion JM, Manolis AJ, Nilsson PM, O'Brien E, Ponikowski P, Redon J, Ruschitzka F, Tamargo J, van Zwieten P, Waeber B, Williams B. 2007 Guidelines for the management of arterial hypertension: The Task Force for the Management of Arterial Hypertension of the European Society of Hypertension (ESH) and of the European Society of Cardiology (ESC). Eur Heart J. 2007;28:1462-536. 
65. Cortigiani L, Paolini EA, Nannini E. Dipyridamole stress echocardiography for risk stratification in hypertensive patients with chest pain. Circulation. 1998; 98:2855-9.

66. Mondillo S, Agricola E, Ammaturo T, Guerrini F, Barbati R, Focardi M, Picchi A, Ballo P, Nami R. Prognostic value of dipyridamole stress echocardiography in hypertensive patients with left ventricular hypertrophy, chest pain and resting electrocardiographic repolarization abnormalities. Can J Cardiol. 2001;17:571-7.

67. Cortigiani L, Coletta C, Bigi R, Amici E, Desideri A, Odoguardi L. Clinical, exercise electrocardiographic, and pharmacologic stress echocardiographic findings for risk stratification of hypertensive patients with chest pain. Am J Cardiol. 2003;9:941-5.

68. Marwick TH, Case C, Sawada S, Vasey C, Thomas JD. Prediction of outcomes in hypertensive patients with suspected coronary disease. Hypertension. 2002;39:1113-8.

69. Bigi R, Bax JJ, van Domburg RT, Elhendy A, Cortigiani L, Schinkel AFL, Fiorentini C, Poldermans D. Simultaneous echocardiography and myocardial perfusion single photon emission computed tomography associated with dobutamine stress to predict long-term cardiac mortality in normotensive and hypertensive patients. J Hypertens. 2005;23:1409-15.

70. Sozzi FB, Elhendy A, Rizzello V, van Domburg RT, Kertai M, Vourvouri E, Schinkel AF, Bax JJ, Roelandt JR, Poldermans D. Prognostic value of dobutamine stress echocardiography in patients with systemic hypertension and known or suspected coronary artery disease. Am J Cardiol. 2004;94:733-9.

71. Cicala S, de Simone G, Roman MJ, Best LG, Lee ET, Wang W, Welty TK, Galloway JM, Howard BV, Devereux RB. Prevalence and prognostic significance of wall-motion abnormalities in adults without clinically recognized cardiovascular disease: the strong heart study. Circulation. 2007;116:143-50.

72. Cortigiani L, Bigi R, Landi P, Bovenzi F, Picano E, Sicari R. Prognostic implication of stress echocardiography in 6214 hypertensive and 5328 normotensive patients. Eur Heart J. 2011;32:1509-18.

73. Hennessy TG, Codd MB, Kane G, McCarthy C, McCann HA, Sugrue DD. Evaluation of patients with diabetes mellitus for coronary artery disease using dobutamine stress echocardiography. Coron Artery Dis. 1997:8:171-4.

74. Elhendy A, van Domburg RT, Poldermans D, Bax JJ, Nierop PR, Geleijnse ML, Roelandt JR. Safety and feasibility of dobutamine-atropine stress echocardiography for the diagnosis of coronary artery disease in diabetic patients unable to perform an exercise stress test. Diabetes Care. 1998;21:1797-802.

75. Griffin ME, Nikookam K, Teh MM, McCann H, O'Meara NM, Firth RG. Dobutamine stress echocardiography: false positive scans in proteinuric patients with type 1 diabetes mellitus at high risk of ischaemic heart disease. Diabet Med. 1998;15:427-30.

76. Young LH, Wackers FJ, Chyun DA, Davey JA, Barrett EJ, Taillefer R, Heller GV, Iskandrian AE, Wittlin SD, Filipchuk N, Ratner RE, Inzucchi SE. Cardiac outcomes after screening for asymptomatic coronary artery disease in patients with type 2 diabetes: the DIAD study: a randomized controlled trial. JAMA. 2009;301:1547-55.

77. Cortigiani L, Sicari R, Desideri A, Bigi R, Bovenzi F, Picano E, VIDA (Viability Identification With Dobutamine Administration) Study Group. Dobutamine stress echocardiography and the effect of revascularization on outcome in diabetic and non-diabetic patients with chronic ischaemic left ventricular dysfunction. Eur J Heart Fail. 2007;9:1038-43.

78. Elhendy A, Arruda AM, Mahoney DW, Pellikka PA. Prognostic stratification of diabetic patients by exercise echocardiography. J Am Coll Cardiol. 2001;37: 1551-7

79. Bigi R, Desideri A, Cortigiani L, Bax JJ, Celegon L, Fiorentini C. Stress echocardiography for risk stratification of diabetic patients with known or suspected coronary artery disease. Diabetes Care. 2001;24:1596-601.

80. Kamalesh M, Matorin R, Sawada S. Prognostic value of a negative stress echocardiographic study in diabetic patients. Am Heart J. 2002;143:163-8.

81. Marwick TH, Case C, Sawada S, Vasey C, Short L, Lauer M. Use of stress echocardiography to predict mortality in patients with diabetes and known or suspected coronary artery disease. Diabetes Care. 2002;25:1042-8.

82. Chaowalit N, Arruda AL, McCully RB, Bailey KR, Pellikka PA. Dobutamine stress echocardiography in patients with diabetes mellitus: enhanced prognostic prediction using a simple risk score. J Am Coll Cardiol. 2006;47:1029-36.

83. van der Sijde JN, Boiten HJ, Sozzi FB, Elhendy A, van Domburg RT, Schinkel AF. Long-term prognostic value of dobutamine stress echocardiography in diabetic patients with limited exercise capability: a 13-year follow-up study. Diabetes Care. 2012;35:634-9.
84. Cortigiani L, Bigi R, Sicari R, Rigo F, Bovenzi F, Picano E. Comparison of prognostic value of pharmacologic stress echocardiography in chest pain patients with versus without diabetes mellitus and positive exercise electrocardiography. Am J Cardiol. 2007;100:1744-9.

85. Cortigiani L, Borelli L, Raciti M, Bovenzi F, Picano E, Molinaro S, Sicari R. Prediction of mortality by stress echocardiography in 2835 diabetic and 11 305 nondiabetic patients. Circ Cardiovasc Imaging. 2015;8(5). doi: 10.1161/ CIRCIMAGING.114.002757

86. Picano E, Vañó E, Rehani MM, Cuocolo A, Mont L, Bodi V, Bar O, Maccia C, Pierard L, Sicari R, Plein S, Mahrholdt H, Lancellotti P, Knuuti J, Heidbuchel H, Di Mario C, Badano LP. The appropriate and justified use of medical radiation in cardiovascular imaging: a position document of the ESC Associations of Cardiovascular Imaging, Percutaneous Cardiovascular Interventions and Electrophysiology. Eur Heart J. 2014;35:665-72.

87. Giri S, Shaw LJ, Murthy DR, Travin MI, Miller DD, Hachamovitch R, BorgesNeto S, Berman DS, Waters DD, Heller GV. Impact of diabetes on the risk stratification using stress single-photon emission computed tomography myocardial perfusion imaging in patients with symptoms suggestive of coronary artery disease. Circulation. 2002;105:32-40.

88. Masini M, Picano E, Lattanzi F, Distante A, L'Abbate A. High-dose dipyridamole echocardiography test in women: correlation with exercise-electrocardiography test and coronary arteriography. J Am Coll Cardiol. 1998;12:682-5.

89. Marwick TH, Anderson T, Williams MJ, Haluska B, Melin JA, Pashkow F, Thomas JD. Exercise echocardiography is an accurate and cost-efficient technique for detection of coronary artery disease in women. J Am Coll Cardiol. 1995;26:335-41.

90. Elhendy A, van Domburg RT, Bax JJ, Nierop PR, Geleijnse ML, Ibrahim MM, Roelandt JR. Noninvasive diagnosis of coronary artery stenosis in women with limited exercise capacity: comparison of dobutamine stress echocardiography and 99mTc sestamibi single-photon emission CT. Chest. 1998;114:1097-104.

91. Cortigiani L, Sicari R, Bigi R, Landi P, Bovenzi F, Picano E. Impact of gender on risk stratification by stress echocardiography. Am J Med. 2009;122:301-9.

92. Cortigiani L, Dodi C, Paolini EA, Bernardi D, Bruno G, Nannini E. Prognostic value of pharmacological stress echocardiography in women with chest pain and unknown coronary artery disease. J Am Coll Cardiol. 1998;32:1975-81.

93. Dodi C, Cortigiani L, Masini M, Olivotto I, Azzarelli A, Nannini E. The incremental prognostic value of stress echo over exercise electrocardiography in women with chest pain of unknown origin. Eur Heart J. 2001:22:145-52.

94. Cortigiani L, Gigli G, Vallebona A, Mariani PR, Bigi R, Desideri A. The stress echo prognostic gender gap. Eur J Echocardiogr. 2001;2:132-8.

95. Mairesse GH, Marwick TH, Arnese M, Vanoverschelde JL, Cornel JH, Detry JM Melin JA, Fioretti PM. Improved identification of coronary artery disease in patients with left bundle branch block by the use of dobutamine stress echocardiography and comparison with myocardial perfusion tomography. Am J Cardiol. 1995;76:321-5

96. Geleijnse ML, Vigna G, Kasprzak JD, Rambaldi R, Salvatori MP, Elhendy A, Cornel $J$ H, Fioretti PM, Roelandt JR. Usefulness and limitations of dobutamine-atropine stress echocardiography for the diagnosis of coronary artery disease in patients with left bundle branch block. Eur Heart J. 2000;21:1666-73.

97. Cortigiani L, Picano E, Vigna C, Lattanzi F, Coletta C, Mariotti E, Bigi R. Prognostic value of pharmacologic stress echocardiography in patients with left bundle branch block. Am J Med. 2001;110:361-9.

98. Fleisher LA, Fleischmann KE, Auerbach AD, Barnason SA, Beckman JA, Bozkurt B, Davila-Roman VG, Gerhard-Herman MD, Holly TA, Kane GC, Marine JE, Nelson MT, Spencer CC, Thompson A, Ting HH, Uretsky BF, Wijeysundera DN. 2014 ACC/AHA guideline on perioperative cardiovascular evaluation and management of patients undergoing noncardiac surgery: a report of the American College of Cardiology/American Heart Association Task Force on practice guidelines. J Am Coll Cardiol. 2014;64:e77-137.

99. Kristensen SD, Knuuti J, Saraste A, Anker S, Bøtker HE, Hert SD, Ford I, Gonzalez-Juanatey JR, Gorenek B, Heyndrickx GR, Hoeft A, Huber K, lung B, Kjeldsen KP, Longrois D, Lüscher TF, Pierard L, Pocock S, Price S, Roffi M, Sirnes PA, Sousa-Uva M, Voudris V, Funck-Brentano C, Authors/Task Force Members. 2014 ESC/ESA guidelines on non-cardiac surgery: cardiovascular assessment and management: the Joint Task Force on non-cardiac surgery: cardiovascular assessment and management of the European Society of Cardiology (ESC) and the European Society of Anaesthesiology (ESA). Eur Heart J. 2014:35:2383-431. 
100. Tischler MD, Lee TH, Hirsch AT, et al. Prediction of major cardiac events after peripheral vascular surgery using dipyridamole echocardiography. Am J Cardiol. 1991;68:593-7.

101. Sicari R, Picano E, Lusa AM, et al. The value of dipyridamole echocardiography in risk stratification before vascular surgery. A multicenter study. The EPIC (Echo Persantine International Study) Group-Subproject: risk stratification before major vascular surgery. Eur Heart J. 1995;16:842-7.

102. Rossi E, Citterio F, Vescio MF, et al. Risk stratification of patients undergoing peripheral vascular revascularization by combined resting and dipyridamole echocardiography. Am J Cardiol. 1998:82:306-10.

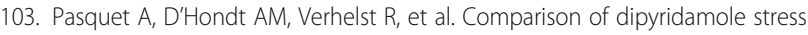
echocardiography and perfusion scintigraphy for cardiac risk stratification in vascular surgery patients. Am J Cardiol. 1998;82:1468-74.

104. Sicari R, Ripoli A, Picano E, on behalf of the EPIC study group, et al. Perioperative prognostic value of dipyridamole echocardiography in vascular surgery: a large-scale multicenter study on 509 patients. Circulation. 1999;100 Suppl 19:|l269-74

105. Zamorano J, Duque A, Baquero $M$, et al. Stress echocardiography in the preoperative evaluation of patients undergoing major vascular surgery. Are results comparable with dipyridamole versus dobutamine stress echo? Rev Esp Cardiol. 2002;55:121-6.

106. Lane RT, Sawada SG, Segar DS, et al. Dobutamine stress echocardiography for assessment of cardiac risk before noncardiac surgery. Am J Cardiol. 1991;68:976-7.

107. Lalka SG, Sawada SG, Dalsing MC, et al. Dobutamine stress echocardiography as a predictor of cardiac events associated with aortic surgery. J Vasc Surg. 1992;15:831-42.

108. Davila-Roman VG, Waggoner AD, Sicard GA, et al. Dobutamine stress echocardiography predicts surgical outcome in patients with an aortic aneurysm and peripheral vascular disease. J Am Coll Cardiol. 1993;21:957-63.

109. Eichelberger JP, Schwarz KQ, Black ER, et al. Predictive value of dobutamine echocardiography just before noncardiac vascular surgery. Am J Cardiol. 1993;72:602-7

110. Poldermans D, Fioretti PM, Forster T, et al. Dobutamine stress echocardiography for assessment of perioperative cardiac risk in patients undergoing major vascular surgery. Circulation. 1993;87:1506-12.

111. Karagiannis SE, Feringa $\mathrm{HH}$, Vidakovic $\mathrm{R}$, et al. Value of myocardial viability estimation using dobutamine stress echocardiography in assessing risk preoperatively before noncardiac vascular surgery in patients with left ventricular ejection fraction <35\%. Am J Cardiol. 2007:99:1555-9.

112. Das MK, Pellikka PA, Mahoney DW, Roger VL, Ohjk MCRB, et al. Assessment of cardiac risk before nonvascular surgery: dobutamine stress echocardiography in 530 patients. J Am Coll Cardiol. 2000;35:1647-53.

113. Beattie WS, Abdelnaem E, Wijeysundera DN, Buckley DN. A meta-analytic comparison of preoperative stress echocardiography and nuclear scintigraphy imaging. Anesth Analg. 2006;102:8-16.

114. Shaw LJ, Eagle KA, Gersh BJ, et al. Meta-analysis of intravenous dipyridamole-thallium-201 imaging (1985 to 1994) and dobutamine echocardiography (1991 to 1994) for risk stratification before vascular imaging. J Am Coll Cardiol. 1996;27:787-98.

115. Kertai MD, Boersma E, Bax JJ, et al. A meta-analysis comparing the prognostic accuracy of six diagnostic tests for predicting perioperative cardiac risk in patients undergoing major vascular surgery. Heart. 2003;89:1327-34

116. Poldermans D, Arnese M, Fioretti PM, et al. Sustained prognostic value of dobutamine stress echocardiography for late cardiac events after major noncardiac vascular surgery. Circulation. 1997;195:53-8.

117. Sicari R, Ripoli A, Picano E, on behalf of the EPIC (Echo Persantine International Cooperative) Study Group, et al. Long-term prognostic value of dipyridamole echocardiography in vascular surgery: a large-scale multicenter study. Coron Artery Dis. 2002;13:49-55.

118. Luscher TF, Gersh B, Landmesser U, Ruschitzka F. Is the panic about betablockers in peri-operative care justified? Eur Heart J. 2014;35:2442-4.

119. Picano E, Pasanisi E, Brown J, et al. A gatekeeper for the gatekeeper: inappropriate referrals to stress echocardiography. Am Heart J. 2007;154:285-90.

120. Gibbons RJ, Miller TD, Hodge D, et al. Application of appropriateness criteria to stress single-photon emission computed tomography sestamibi studies and stress echocardiograms in an academic medical center. J Am Coll Cardiol. 2008:51:1283-9.

121. Mansour IN, Lang RM, Aburuwaida WM, Bhave NM, Ward RP. Evaluation of the clinical application of the ACCF/ASE appropriateness criteria for stress echocardiography. J Am Soc Echocardiogr. 2010;23:1199-204.
122. Cortigiani L, Bigi R, Bovenzi F, Molinaro S, Picano E, Sicari R. Prognostic implication of appropriateness criteria for pharmacologic stress echocardiography performed in an outpatient clinic. Circ Cardiovasc Imaging. 2012;5:298-305.

123. Smart SC, Sawada S, Ryan T, Segar D, Atherton L, Berkovitz K, Bourdillon PD, Feigenbaum $\mathrm{H}$. Low-dose dobutamine echocardiography detects reversible dysfunction after thrombolytic therapy of acute myocardial infarction. Circulation. 1993;88:405-15.

124. Bax JJ, Cornel JH, Visser FC, Fioretti PM, van Lingen A, Reijs AE, Boersma E, Teule GJ, Visser CA. Prediction of recovery of myocardial dysfunction after revascularization. Comparison of fluorine-18 fluorodeoxyglucose/thallium201 SPECT, thallium-201 stress-reinjection SPECT and dobutamine echocardiography. J Am Coll Cardiol. 1996;28:558-64.

125. Bax JJ, Wijns W, Cornel JH, Visser FC, Boersma E, Fioretti PM. Accuracy of currently available techniques for prediction of functional recovery after revascularization in patients with left ventricular dysfunction due to chronic coronary artery disease: comparison of pooled data. J Am Coll Cardiol. 1997;30:1451-60.

126. Picano E, Marzullo P, Gigli G, Reisenhofer B, Parodi O, Distante A, L'Abbate A. Identification of viable myocardium by dipyridamole-induced improvement in regional left ventricular function assessed by echocardiography in myocardial infarction and comparison with thallium scintigraphy at rest. Am J Cardiol. 1992;70:703-10.

127. Varga A, Ostojic M, Djordjevic-Dikic A, Sicari R, Pingitore A, Nedeljkovic I, Picano E. Infra-low dose dipyridamole test. A novel dose regimen for selective assessment of myocardial viability by vasodilator stress echocardiography. Eur Heart J. 1996;17:629-34.

128. Picano E, Ostojic M, Varga A, Sicari R, Djordjevic-Dikic A, Nedeljkovic I, Torres M. Combined low dose dipyridamole-dobutamine stress echocardiography to identify myocardial viability. J Am Coll Cardiol. 1996;27:1422-8.

129. Hoffer EP, Dewe W, Celentano C, Pierard LA. Low-level exercise echocardiography detects contractile reserve and predicts reversible dysfunction after acute myocardial infarction: comparison with low-dose dobutamine echocardiography. J Am Coll Cardiol. 1999;34:989-97.

130. Lu C, Carlino M, Fragasso G, Maisano F, Margonato A, Cappelletti A, Chierchia SL. Enoximone echocardiography for predicting recovery of left ventricular dysfunction after revascularization: a novel test for detecting myocardial viability. Circulation. 2000;101:12551260.

131. Ghio S, Constantin C, Raineri C, Fontana A, Klersy C, Campana C, Tavazzi L. Enoximone echocardiography: a novel test to evaluate left ventricular contractile reserve in patients with heart failure on chronic betablocker therapy. Cardiovasc Ultrasound. 2003;1:13.

132. Baumgartner H, Porenta G, Lau YK, Wutte M, Klaar U, Mehrabi M, Siegel RJ, Czernin J, Laufer G, Sochor H, Schelbert H, Fishbein MC, Maurer G. Assessment of myocardial viability by dobutamine echocardiography, positron emission tomography and thallium-201 SPECT: correlation with histopathology in explanted hearts. J Am Coll Cardiol. 1998;32:1701-8.

133. Williams MJ, Odabashian J, Lauer MS, Thomas JD, Marwick TH. Prognostic value of dobutamine echocardiography in patients with left ventricular dysfunction. J Am Coll Cardiol. 1996;27:132-9.

134. Bax JJ, Poldermans D, Elhendy A, Cornel JH, Boersma E, Rambaldi R, Roelandt JR, Fioretti PM. Improvement of left ventricular ejection fraction, heart failure symptoms and prognosis after revascularization in patients with chronic coronary artery disease and viable myocardium detected by dobutamine stress echocardiography. J Am Coll Cardiol. 1999;34:163-9.

135. Meluzín J, Cerný J, Frélich M, Stetka F, Spinarová L, Popelová J, Stípal R. Prognostic value of the amount of dysfunctional but viable myocardium in revascularized patients with coronary artery disease and left ventricular dysfunction. J Am Coll Cardiol. 1998;32:912-20.

136. Marwick TH, Zuchowski C, Lauer MS, Secknus MA, Williams J, Lytle BW. Functional status and quality of life in patients with heart failure undergoing coronary bypass surgery after assessment of myocardial viability. J Am Coll Cardiol. 1999;33:750-8.

137. Chaudry FA, Tauke JT, Alessandrini RS, Vardi G, Parker MA, Bonow RO. Prognostic implications of myocardial contractile reserve in patients with coronary artery disease and left ventricular dysfunction. J Am Coll Cardiol. 1999;34:730-8.

138. Sicari R, Ripoli A, Picano E, Borges AC, Varga A, Mathias W, Cortigiani L, Bigi R, Heyman J, Polimeno S, Silvestri O, Gimenez V, Caso P, Severino S, Djordjevic-Dikic A, Ostojic M, Baldi C, Seveso G, Petix N, VIDA (Viability Identification With Dipyridamole Administration) Study Group. The 
prognostic value of myocardial viability recognized by low dose dipyridamole echocardiography in patients with chronic ischaemic left ventricular dysfunction. Eur Heart J. 2001;22:837-44.

139. Sicari R, Picano E, Cortigiani $L$, Borges AC, Varga A, Palagi C, Bigi R, Rossini $R$, Pasanisi E, VIDA (Viability Identification with Dobutamine Administration) Study Group. Prognostic value of myocardial viability recognized by lowdose dobutamine echocardiography in chronic ischaemic left ventricular dysfunction. Am J Cardiol. 2003;92:1263-6.

140. Senior R, Kaul S, Lahiri A. Myocardial viability on echocardiography predicts long-term survival after revascularization in patients with ischaemic congestive heart failure. J Am Coll Cardiol. 1999;33:1848-54.

141. Allman KC, Shaw LJ, Hachamovitch R, Udelson JE. Myocardial viability testing and impact of revascularization on prognosis inpatients with coronary artery disease and left ventricular dysfunction: a meta-analysis. J Am Coll Cardiol. 2002;39:1151-8.

142. Rizzello V, Poldermans D, Schinkel AF, Biagini E, Boersma E, Elhendy A, Sozzi FB, Maat A, Crea F, Roelandt JR, Bax JJ. Long term prognostic value of myocardial viability and ischaemia during dobutamine stress echocardiography in patients with ischaemic cardiomyopathy undergoing coronary revascularisation. Heart. 2006;92:239-44.

143. Ciampi Q, Pratali L, Citro R, Piacenti M, Villari B, Picano E. Identification of responders to cardiac resynchronization therapy by contractile reserve during stress echocardiography. Eur J Heart Fail. 2009;11:489-96.

144. Moonen M, Senechal M, Cosyns B, Melon P, Nellessen E, Pierard L, Lancellotti $P$. Impact of contractile reserve on acute response to cardiac resynchronization therapy. Cardiovasc Ultrasound. 2008;6:65.

145. Cortigiani L, Rigo F, Gherardi S, Bovenzi F, Molinaro S, Picano E, Sicari R. Coronary flow reserve during dipyridamole stress echocardiography predicts mortality. JACC Cardiovasc Imaging. 2012;5:1079-85.

146. Cortigiani L, Rigo F, Gherardi S, Sicari R, Galderisi M, Bovenzi F, Picano E. Additional prognostic value of coronary flow reserve in diabetic and nondiabetic patients with negative dipyridamole stress echocardiography by wall motion criteria. J Am Coll Cardiol. 2007;50:1354-61.

147. Cortigiani L, Rigo F, Gherardi S, Galderisi M, Bovenzi F, Picano E, Sicari R. Diagnostic and prognostic value of Doppler echocardiographic coronary flow reserve in left anterior descending artery in hypertensive and normotensive patients. Heart. 2011;97:1758-65.

148. Rigo F, Sicari R, Gherardi S, Djordjevic-Dikic A, Cortigiani L, Picano E. Prognostic value of coronary flow reserve in medically treated patients with left anterior descending coronary disease with stenosis 51\%-75\% in diameter. Am J Cardiol. 2007;100:1527-31.

149. Cortigiani L, Rigo F, Gherardi S, Bovenzi F, Molinaro S, Picano E, Sicari R. Prognostic implication of Doppler echocardiographic derived coronary flow reserve in patients with left bundle branch block. Eur Heart J. 2013;34:364-73.

150. Sicari R, Rigo F, Cortigiani L, Gherardi S, Galderisi M, Picano E. Long-term survival of patients with chest pain syndrome and angiographically normal or near normal coronary arteries: the additional prognostic value of coronary flow reserve. Am J Cardiol. 2009;103:626-31.

151. Cortigiani L, Rigo F, Gherardi S, Galderisi M, Bovenzi F, Picano E, Sicari R. Prognostic meaning of coronary microvascular disease in type 2 diabetes mellitus. A transthoracic Doppler echocardiographic study. J Am Soc Echocardiogr. 2014;27:742-8.

152. Gaibazzi N, Reverberi C, Lorenzoni V, Molinaro S, Porter TR. Prognostic value of high-dose dipyridamole stress myocardial contrast perfusion echocardiography. Circulation. 2012;126:1217-24.

153. Huang R, Abdelmoneim SS, Nhola LF, Mulvagh SL. Relationship between $\mathrm{HbA1c}$ and myocardial blood flow reserve in patients with type 2 diabetes mellitus: noninvasive assessment using real-time myocardial perfusion echocardiography. J Diabetes Res. 2014;2014:243518. doi:10.1155/2014/ 243518. Epub 2014 Jul 2

154. Lowenstein JA, Caniggia C, Rousse G, Amor M, Sánchez ME, Alasia D, Casso N, García A, Zambrana G, Lowenstein Haber DM, Darú V. Coronary flow velocity reserve during pharmacologic stress echocardiography with normal contractility adds important prognostic value in diabetic and nondiabetic patients. J Am Soc Echocardiogr. 2014;27:1113-9.

155. Sicari R, Rigo F, Gherardi S, Galderisi M, Cortigiani L, Picano E. The prognostic value of Doppler echocardiographic-derived coronary flow reserve is not affected by concomitant antiischemic therapy at the time of testing. Am Heart J. 2008; 156:573-9.

156. Mor-Avi V, Lang RM, Badano LP, Belohlavek M, Cardim NM, Derumeaux G, Galderisi M, Marwick T, Nagueh SF, Sengupta PP, Sicari R, Smiseth OA,
Smulevitz B, Takeuchi M, Thomas JD, Vannan M, Voigt JU, Zamorano JL. Current and evolving echocardiographic techniques for the quantitative evaluation of cardiac mechanics: ASE/EAE consensus statement on methodology and indications endorsed by the Japanese Society of Echocardiography. Eur J Echocardiogr. 2011;12:167-205.

157. Lang RM, Badano LP, Tsang W, Adams DH, Agricola E, Buck T, Faletra FF, Franke A, Hung J, de Isla LP, Kamp O, Kasprzak JD, Lancellotti P, Marwick TH, McCulloch ML, Monaghan MJ, Nihoyannopoulos P, Pandian NG, Pellikka PA, Pepi M, Roberson DA, Shernan SK, Shirali GS, Sugeng L, Ten Cate FJ, Vannan MA, Zamorano JL, Zoghbi WA, American Society of Echocardiography; European Association of Echocardiography. EAE/ASE recommendations for image acquisition and display using three-dimensional echocardiography. Eur Heart J Cardiovasc Imaging. 2012;13:1-46.

158. Crouse LJ, Cheirif J, Hanly DE, Kisslo JA, Labovitz AJ, Raichlen JS, et al. Opacification and border delineation improvement in patients with suboptimal endocardial border definition in routine echocardiography: results of phase III Albunex multicenter trial. J Am Coll Cardiol. 1993;22:1494-500.

159. Fletcher GF, Balady GJ, Amsterdam EA, et al. Exercise standards for testing and training: a statement for healthcare professionals from the American Heart Association. Circulation. 2001;104:1694-740.

160. Varga A, Garcia MA, Picano E, et al. Safety of stress echocardiography (from the International Stress Echo Complication Registry). Am J Cardiol. 2006:98:541-3.

161. Picano E, Marini C, Pirelli S, et al. Safety of intravenous high-dose dipyridamole echocardiography. The Echo-Persantine International Cooperative Study Group. Am J Cardiol. 1992;70:252-8.

162. Picano E, Mathias Jr W, Pingitore A, et al. Safety and tolerability of dobutamine-atropine stress echocardiography: a prospective, multicentre study. Echo Dobutamine International Cooperative Study Group. Lancet. 1994;344:1190-2.

163. Beckmann S, Haug G. National registry 1995-1998 on 150,000 stress echo examinations side effects and complications in 60,448 examinations of the registry 1997-1998. Circulation. 1999;100(Suppl):3401A.

164. Picano E, Pellikka PA. Stress echo applications beyond coronary artery disease. Eur Heart J. 2014;35:1033-40.

\section{Submit your next manuscript to BioMed Central and we will help you at every step:}

- We accept pre-submission inquiries

- Our selector tool helps you to find the most relevant journal

- We provide round the clock customer support

- Convenient online submission

- Thorough peer review

- Inclusion in PubMed and all major indexing services

- Maximum visibility for your research

Submit your manuscript at www.biomedcentral.com/submit
) Biomed Central 